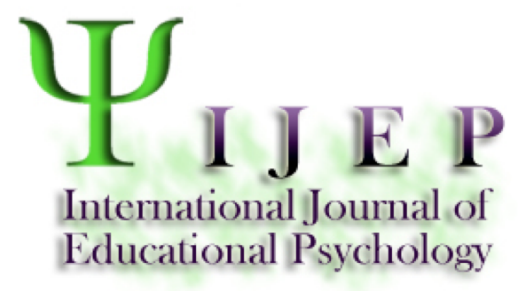

\title{
Volume 6, Number 1
}

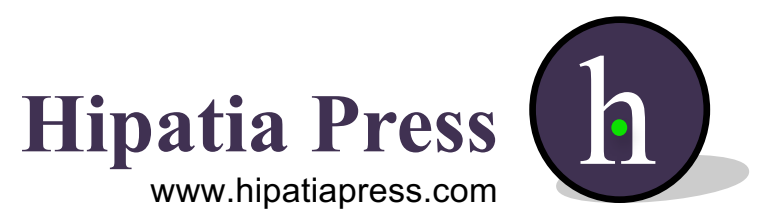

Proactive and Reactive Aggressive Behavior in Bullying: The Role of Values - Natalia Jara, Jose A. Casas, Rosario Ortega-Ruiz..

Articles A Cross-Cultural Validation of the MUSIC $₫$ Model of Academic Motivation Inventory: Evidence from Chinese- and Spanish-Speaking University Students - Brett D. Jones, Ming Li, and Juan M. Cruz..........25

Japanese and Korean Kindergartners' Perspectives of Play Using Photos - Satomi Izumi-Taylor, Yeonsun Ro, Jihee Han, Yoko Ito.

Achievement Emotions and Achievement Goals in Support of the Convergent, Divergent and Criterion Validity of the Spanish-Cognitive Test Anxiety Scale - Javier Sánchez-Rosas, Luis Alberto Furlan. 
Instructions for authors, subscriptions and further details:

http://ijep.hipatiapress.com

\section{Proactive and Reactive Aggressive Behavior in Bullying: The Role of Values}

Natalia Jara, Jose A. Casas, Rosario Ortega-Ruiz ${ }^{1}$

1) Universidad de Córdoba

Date of publication: February $24^{\text {th }}, 2017$

Edition period: February 2017 - June 2017

To cite this article: Jara, N; Casas, J.A. \& Ortega-Ruiz, R. (2017).

Proactive and Reactive Aggressive Behavior in Bullying: The Role of Values. International Journal of Educational Psychology, 6(1), 1-24. doi: 10.17583/ijep.2017.2515

To link this article: http://dx.doi.org/10.17583/ijep.2017.2515

\section{PLEASE SCROLL DOWN FOR ARTICLE}

The terms and conditions of use are related to the Open Journal System and to Creative Commons Attribution License (CC-BY). 


\title{
Proactive and Reactive Aggressive Behavior in Bullying: The Role of Values
}

\author{
Natalia Jara \\ Jose A. Casas \\ Rosario Ortega-Ruiz \\ Universidad de Córdoba \\ Universidad de Córdoba \\ Universidad de Córdoba
}

\begin{abstract}
The study of violence and bullying in schools is a line of scientific research that has contributed significantly to knowledge on human aggressiveness, especially in children and adolescents. This article shows that there are two patterns of aggressive behavior: proactive and reactive. Both are present in bullying, as are other psychological aspects pertaining to the individuals involved, such as basic personality traits, self-esteem and values. This study links both proactive and reactive behavioral patterns to involvement and non-involvement in school bullying. The results reveal that basic personality traits, such as neuroticism, have a direct impact on proactive and reactive bullying, as do the social and individual dimensions of self-esteem and social and moral values. These findings confirm that variables relating to personal and social values are, in turn, related to proactive and reactive aggressive behavior in bullying for those involved and not involved in bullying. However, they also highlight that while aggressors engage in more proactive aggressive behavior, reactive aggression is more frequent among victims.
\end{abstract}

Keywords: Aggressive Behavior, Bullying, Personality Traits, Self-esteem and Values 


\section{Agresividad Proactiva y Reactiva en el Fenómeno Bullying: El Papel de los Valores}

Natalia Jara

Universidad de Córdoba
Jose A. Casas

Universidad de Córdoba
Rosario Ortega-Ruiz

Universidad de Córdoba

\section{Resumen}

La investigación sobre violencia escolar y bullying ha resultado ser una línea de de trabajo científico que ha contribuido de forma importante a los estudios sobre agresividad humana, especialmente en los años de la niñez y la adolescencia. El trabajo que este artículo presenta revela que la conducta agresiva en sus dos patrones básicos: conducta agresiva proactiva y conducta agresiva reactiva tienen presencia en el fenómeno bullying, así como otros aspectos de la psicología de los implicados (por ej. Aspectos básicos de personalidad, la autoestima, y los valores. Este estudio relaciona ambos patrones (reactivo y proactivo) con la implicación o no implicación en acoso escolar. Los resultados manifiestan que aspectos básicos de la personalidad, como el neuroticismo, inciden en la implicación en bullying tanto de forma proactiva como de forma reactiva, al igual que la autoestima y los valores sociomorales en sus dimensiones social e individual. Los resultados obtenidos en este trabajo confirman que las variables relativas a valores personales y sociales están relacionadas con la agresión reactiva y proactiva en bullying, tanto para la implicación como para la no implicación en el mismo, aunque se destacan como los agresores muestran una mayor presencia del patrón agresivo pro-activo y las víctimas, con una mayor presencia del patrón reactivo.

Palabras clave: Agresividad, acoso, rasgos de la personalidad, autoestima y valores. 
T nterpersonal violence. Labeling certain aggressive behaviors as "violence" is controversial within the field of scientific research. Regarded as an expression of aggressive attitudes and behaviors, violence carries social connotations that hinder the understanding of aggressiveness as a natural universal parameter (Pailing, Boon, \& Egan, 2014). However, violence cannot be assumed to be disconnected from the neurophysiological parameters which underlie all behavior. Violence is an expression of aggressive behavior that has lost many of its natural traits and incorporated others (Ortega, 2010). It often becomes a form of unjustified, immoral and cruel aggression, in which one individual exercises power over another. Aggressive behavior that occurs with a clear intention to harm, is not innate aggression but violence.

In studies on violence and bullying in schools, the concept is well defined. Bullying is a psychosocial phenomenon involving gratuitous, intentional aggression that takes advantage of an imbalance of power between the aggressor and the victim. It also has moral connotations from the perspective of both psychological and ethical-social dimensions, given that it is an immoral abuse of power and ethically reprehensible ( $\mathrm{Xu}$, Raine, Yu, \& Krieg, 2014).

Some authors consider that the concept of violence should be restricted to acts of physical aggression (Olweus, 1993). However, in line with the definition of the $\mathrm{WHO}$, an increasing number of researchers understand violence to include psychological, verbal and moral aggression. Ortega (2010) argued that violence is a form of aggressive behavior that comprises socio-moral elements which denote a breakdown in communication patterns and the mitigation of conflicts of interest via the usual channels of communication and dialogue. All violence includes, to some extent, the transgression of the norms of coexistence implicit in social regulation. Violence implies the use of force or power to dominate a situation in favor of the interests of the violent individual; however, it also requires the competent control of certain relational-type abilities, which is why moral injury is also considered violence (Pailing et al., 2014).

Some studies have concluded that violence is a long-term, stable construct expressed in different types of aggressive behavior throughout the life of a violent individual (Hart, Hofmann, Edelstein, \& Keller, 1997). This 


\section{Jara, Casas \& Ortega-Ruiz-Aggressive Behaviour}

leads us to question why some human beings fail to transform basic aggressive patterns of behavior into non-harmful verbal forms of communication in order to resolve conflicts of interest that arise in human relationships in a non-violent way. This suggests that it is necessary to go beyond the notion of the possible inheritability of aggressive behavior to inquire into the relationship between violence and personal and social moral criteria.

From a purely descriptive perspective, aggressive behavior can be proactive or reactive. There is no doubt that both predation and revenge can be grounds for violent acts. Some studies identify aggressive action as a response to an aggression received earlier. The figure of the aggressive victim or the victimized aggressor in bullying responds to the difficulty in clarifying the action-reaction interplay which is frequently implicit in aggressive actions that occur within relatively stable interpersonal relationships. As mentioned, certain aspects of interpersonal violence are related to social judgments, which underlie the intention or not to do harm (Bandura, 1973).

On occasion, it has been argued that there exists a spiral of violence, suggesting that the more aggressive acts an individual commits the more likely he or she is to engage in serious violent behavior in the future, with adolescence and early adulthood being the most vulnerable periods for this type of violence (Rutter, Giller, \& Hagell, 2000). Longitudinal studies have predicted that aggressive behavior exhibited in early childhood gives rise to a personality trait that can manifest itself in progressively more intense violent acts (Hart et al., 1997). It has been reported that the highest levels of violence occur during early adolescence (10 to 13 years old) and that violent behavior is also significant in later years (14-17 years old) (Pailing et al., 2014).

\section{Bullying in Adolescence: Aggressors and Victims}

Violence in schools comprises a wide range of aggressive or antisocial behavior such as disruptive acts, lack of respect for conventional discipline, absenteeism, vandalism and many more. Among these types of behavior, physical, verbal, psychological and relational aggression by one student or 
group of students against others who have fewer resources to defend themselves are the types of interpersonal violence that seem to be the most significant problem related to aggressive behavior in the school setting (Del Barrio, Martín, Almeida, \& Barrios, 2003). Although bullying is quite widespread throughout primary schooling, it does not appear to be as serious as it later becomes in adolescence.

The importance of adolescence as a stage of change and personality formation means that studies on violence and bullying in schools have become increasingly abundant and part of the approach to the psychology of aggressiveness. In this regard, some studies have highlighted that harassment among schoolchildren takes the form of role play in which a student assuming a dominant role, alone or in the company of others, intentionally, unjustifiably and protractedly attacks another student who assumes a submissive role inappropriate of the egalitarian social relationship that would morally correspond to them (Ortega, 2010). Given that this is a social phenomenon which is sustained over time and in which observers and other schoolchildren who support, reject or consent to what is happening inevitably become involved, the social problem becomes even more complex and poses knock-on negative effects in the school environment.

Victims of bullying do not display common personality traits, nor can it be said that they have a unique pattern of individual traits; in fact, no common risk factors have been found. However, in general, they frequently exhibit poor social skills and social adjustment. As such, many of them are unpopular and not highly regarded by others. A well-defined type is the socalled provocative victim, children who display controversial behavior and, although heavily involved in social networking, tend to fail socially. They draw attention to themselves by making social gaffes and are often used as scapegoats by their companions. Children who have been overprotected in their family environment and perhaps somewhat naïve are also, more often than not, victims of bullies. In addition, children who belong to different social groups are perceived as being weaker and those with a disability or requiring special educational needs are also victims of bullying (Zych, Ortega-Ruiz, \& Del Rey, 2015).

With regard to aggressors, leading studies conclude that they are usually physically and sometimes psychologically stronger than others, are 


\section{Jara, Casas \& Ortega-Ruiz-Aggressive Behaviour}

impulsive, have a low tolerance for frustration and find it difficult to obey rules and abide by norms. They engage in negative relationships with adults, often perform poorly at school and display a lack of self-criticism, yet are popular and highly regarded by their peers. Their social problems increase with age, but in the school years it is easy for them to be surrounded by fellow schoolmates, some of whom follow in their footsteps (Pellegrini, Bartini, \& Brooks, 1999; Salmivalli \& Nieminen, 2002). Bullying aggressors show a greater tendency to identify with the acknowledged dominionsubmission model (Ortega-Ruiz \& Mora-Merchán, 2008) by adopting the dominant role and demanding that their victim obey their command. They also find it more difficult to respond appropriately to the emotional state of others (affective empathy). However, they tend to express self-complacency with their actions and relationships, although they do not display a high level of self-esteem and self-awareness in their social efficacy. Moreover, although they are usually open to others, they avoid engaging in behavior that is susceptible of being branded as inappropriate by adults (Stoudt, 2006).

Personal variables relating to aggressive behavior include temperamental characteristics such as neuroticism, impulsivity and the compulsive search for new sensations (Caprara \& Pastorelli, 1993), as well as emotional variables, such as the aforementioned lack of empathy, inconsistency and the lack of a good hierarchical values system (Samper, Tur, Mestre, \& Cortés, 2008). With regard to the relationship between self-esteem and aggressive behavior, the studies are inconclusive. Some studies indicate a weak correlation between aggression and self-esteem (McCarthy \& Hoge, 1984), while others have found links between low self-esteem and a greater presence of threatening and aggressive behavior (Marsh, Parada, Yeung, \& Healey, 2001). Still others have found a positive relationship between low self-esteem and risk factors for antisocial and aggressive behavior. The personality of the aggressor is fundamentally proactive given that it is usually the aggressor who initiates an aggression. However, the complex process behind the social and temporal structure of bullying can also encompass reactive behaviors from victims who respond in the "wrong way" to provocation from an aggressor who displays a sustained strategy of 
intimidation and control; all of which makes it difficult to identify a single pattern (Dodge, 1997).

\section{Personal and Social Moral Values in Bullying}

In addition to the personality traits of its protagonists, the social context in which bullying occurs plays a significant role; particularly peer social networks and the immediate social environment, that is, the formal grouping structures established by the educational system in classrooms and during leisure and recreational activities supervised by teachers. Undeniably, bullying is related to opportunities for sociability and experiences with others (Poulin \& Boivin, 2000). For example, proactive aggressive adolescents tend to associate with proactive aggressive adolescents, but this does not appear to be the case when violence is reactive (Poulin \& Boivin, 1999). Perhaps this is based on the fact that children who exhibit reactive aggressive behaviors are negatively evaluated by their peer group, while proactive aggressors are socially valued for their often humoristic and leadership qualities (Dodge \& Coie, 1987).

As mentioned above, ethical values and criteria are compromised in bullying and may be different for proactive and reactive aggressors. Although there is little research on moral standards and bullying, the results of studies dealing with this issue are controversial. Some studies have found very few differences between the way aggressors and individuals not involved in bullying view the classroom (Cerezo, 2002). Salmivalli and Nieminen (2002) highlighted the importance of hierarchical personal values as well as the interaction of personal values and shared social values.

In this regard, the theory of moral disengagement (Bandura, 1999) has become a good paradigm for the study of values and social behavior. Bandura proposed the concept of moral disengagement to describe the cognitive process of evading critical input evidenced by the hierarchy of values in the face of the incongruity between what one thinks and what one does. Based on this theory, some studies have concluded that aggressors use more mechanisms of moral disengagement than victims (Ortega-Ruiz, Jiménez, \& Menesini, 2002). 


\section{Jara, Casas \& Ortega-Ruiz-Aggressive Behaviour}

\section{Proactive and Reactive Aggressive Behavior in Bullying}

Dodge (1997) analyzed the cognitive mechanisms that characterize aggression and identified two major patterns: proactive and reactive aggression. The distinction between proactive and reactive aggression has an important potential for supporting and clarifying ethological assumptions (Dodge \& Schwartz, 1997). Reactive aggression is based on the frustrationaggression model that occurs as a reaction to a threat and is often associated with intense emotions, high levels of impulsivity and hostility, and deficits in information processing (Raine et al., 2006) where the aggressor is frequently guided by the motivation to harm others without a specific objective.

An explanation for proactive aggression can be found in Bandura's (1973) social learning model as a strategy that intends to reach a goal, an objective or some kind of benefit through cold-blooded and instrumental behavior that involves harming others (Raine et al., 2006). Some studies have shown that the factors that lead to proactive aggression and the factors that lead to reactive aggression are interrelated, although it might be reasonable to assume that proactive and reactive aggression have different etiologies (Crick \& Dodge, 1996). It has also been demonstrated that both types of behavior are linked to different personality traits, styles of sociability, and especially each individual's personal and social values (Dodge \& Coie, 1987). In this respect, beliefs in social values regarding unjustified aggression, such as bullying, seem to be more closely associated with proactive rather than reactive aggression (Crick \& Dodge, 1996).

In this scientific context, our study has two main objectives. First, to observe the level of involvement in bullying in a sample of adolescents from Cordoba, Spain, with the aim of determining the proactive and reactive aggressive behavior patterns of those involved in bullying. And second, to define the relationship between proactive and reactive aggressive behavior patterns (Crick \& Dodge, 1996) of those involved and not involved in bullying, taking into account self-esteem as a slightly controversial measure of personality, as well as the social and individual dimensions of social and moral values. 


\section{Methodology}

\section{Participants}

A total of 326 students ( $\mathrm{n}=158 ; 48.5 \%$ female) from two secondary public schools, one in the capital city and the other in the province of Cordoba, participated in the study. The participants' age ranged from 12 to 18 years ( $\mathrm{M}=14.61 ; \mathrm{SD}=1.26$ for both sexes). The data was collected by means of convenience sampling, until completing the sample.

\section{Instruments}

The Big Five Inventory (BFI-10) (Rammstedt \& John, 2007), a questionnaire that comprises 10 items to measure the five major personality traits (extraversion, agreeableness, conscientiousness, neuroticism and openness to experience) was used. Examples of the items are: "I see myself as someone who is reserved" and "I see myself as someone who gets nervous easily". The responses are scored a 5-point Likert-type scale from "Strongly disagree" to "Strongly agree." The reliability of the scale is acceptable with levels of $\alpha=.83$ for the general questionnaire; $\alpha=.90$ for extraversion; $\alpha=.78$ for agreeableness; $\alpha=.84$ for conscientiousness; $\alpha=$ .88 for neuroticism, and $\alpha=.80$ for openness to experience (Rammstedt $\&$ John, 2007).

The validated version in Spanish of the European Bullying Intervention Project Questionnaire (EBIPQ) (Ortega-Ruiz, Del Rey, \& Casas, 2016) comprises 14 items with 5 Likert-type scale response options that measure the frequency of bullying behavior and range from "Never" to "More than once a week". The EBIQP consists of two scales. The aggression scale includes items such as "I have hit, kicked or pushed someone"; while the victimization scale includes items such as "Someone has hit, kicked or pushed me." The reliability levels are $\alpha=.82$ for the total number of subjects; $\alpha=.75$ for aggression, and $\alpha=.84$ of victimization. The questionnaire has been validated in six European countries (Spain, Poland, Italy, Germany, the United Kingdom and Greece) for use in different programs. 
The Rosenberg self-esteem scale (Pullmann \& Allik, 2000) is a 10-item Likert scale to measure self-esteem and self-acceptance. The items are answered on a 4 point scale from "Strongly Disagree" to "Strongly Agree". Examples of the items are "I am able to do things as well as most other people" or "On the whole, I am satisfied with myself". The RSES is the most widely used assessment tool to measure general self-esteem, which is understood as a general evaluation of an individual's worth as a human being (Pullmann \& Allik, 2000). The reliability level of the scale is $\alpha=.84$.

The values scale (Oliva, 2011) comprises 24 items to evaluate the importance that adolescent children give to a set of values involved in their positive development. The answers to the options range from 1 to 7 , with 1 being "Not important" and 7 "Most important" with items such as "Being admired by others." The scale measures three dimensions structured into: social values, personal values and individual values, whose levels of reliability are $\alpha=.87 ; \mathrm{a}=.82$, and $\alpha=.74$, respectively. The overall reliability of the scale is $\alpha=.88$.

The Reactive-Proactive Aggression Questionnaire (RPQ) designed by Raine et al. (2006) measures both types of aggressive behavior in adolescents. It consists of 23 items based on the proactive (instrumental) motivational dimension model such as "Had fights with others to prove who was on top", and in the reactive (hostility) dimension such as "Yelled when annoyed". A Likert scale is used to rate each item according to its frequency of occurrence from 0 to 2 where 0 is "Never", 1 is "Sometimes" and 2 is "Often." The reliability of the scale is $\alpha=.84$ for all items; $\alpha=.81$ for proactive aggression and $\alpha=.74$ for reactive aggression.

\section{Procedure}

The schools were contacted to invite them to participate in the study and permission was obtained to administer the questionnaires. The questionnaires were administered in groups with an approximate duration of 25-30 minutes. All participants were informed that the data would be confidential and anonymous. Participation was voluntary and also confidential. Data were gathered in accordance with the ethical standards and general principles of the American Psychological Association (APA). 


\section{Data Analysis}

A univariate descriptive analysis was performed for all the variables studied. In order to achieve the objectives proposed in the study, we first selected students involved and not involved in bullying in order to analyze the data separately. For the EBIPQ, a theoretical model was used in which the respondents who marked 2 ("Once or twice") or 1 ("Never") on the scale items were classified as not being involved in bullying, that is, these subjects denied any type of involvement according to the theoretical criteria on bullying involvement. We then analyzed the data of subjects who marked 3 ("Once or twice a month") or more on all the scale items. In order to obtain the percentages of aggressors and victims, those involved in bullying were analyzed using another theoretical model. According to this model, respondents who score 3 or more (i.e., once or twice a month or more) on items related to aggression or 2 or less on items related to victimization are aggressors. With victims the opposite occurs. Those who score 3 or more on the items related to victimization and 2 or less on the items related to aggression are considered victims. Respondents who score 3 or more on both scales correspond to the role of bully-victims.

We then performed an analysis using structural equation modeling. In the analysis, we used the maximum robustness estimation method due to the fact that the variables are of an ordinal nature and do not satisfy the assumption of normality. Furthermore, following the recommendations of $\mathrm{Hu}$ and Bentler (1999), we used a combination of several indices to contrast the appropriateness of the proposed models. The chi-square statistic in comparison to its degrees of freedom, the comparative fit index (CFI), the goodness of fit index (GFI), the Tucker-Lewis index (TLI), the root mean square error of approximation (RMSEA) and the root mean square residual (RMR) index were used. The standardized regression coefficients included in the model were estimated according to their level of significance. The data were analyzed using SPSS version 20 and EQS 6.1 statistical software. This software allows for polyclonal correlations, which are more suitable for variables of this type (Flora \& Curran, 2004). 
10 Jara, Casas \& Ortega-Ruiz-Aggressive Behaviour

\section{Results}

A univariate analysis was performed on all data in order to obtain the means and standard deviations of the variables (see Table 1). Following the theoretical criteria described above, the percentage of involvement in bullying was calculated by differentiating the three main roles: aggressors $(n$ $=45 ; 13.80 \%)$, victims $(n=54 ; 16.56 \%)$ and bully-victims $(n=12 ; 3.68 \%)$ (See Tables 2, 3 and 4).

Table 1.

Basic descriptions

\begin{tabular}{|c|c|c|c|c|c|c|c|c|}
\hline & $\mathrm{N}$ & Min I & Max & M & SD & Variance & Skewness & Kurtosis \\
\hline Proactive Aggression & 326 & 1 & 3 & 1.31 & .321 & .103 & 1.439 .135 & 51.710 .270 \\
\hline Reactive Aggression & 326 & 1 & 3 & 1.81 & .345 & .119 & .378 .135 & $5 \quad .166 \quad .270$ \\
\hline Aggression Bullying & 326 & 1 & 5 & 1.75 & .653 & .427 & 1.587 .135 & 53.560 .269 \\
\hline Victimization Bullying & 326 & 1 & 5 & 1.89 & .761 & .579 & 1.327 .135 & 52.067 .269 \\
\hline Self-esteem & 326 & 1 & 3 & 2.38 & .271 & .073 & -.117 .135 & $5 \quad .757 \quad .269$ \\
\hline Extraversion & 326 & 1 & 5 & 3.54 & .935 & .874 & -.065 .135 & $5-.695 .269$ \\
\hline Agree & 326 & 2 & 5 & 3.51 & .806 & .649 & -.147 .135 & $5-.340 .269$ \\
\hline Conscier & 326 & 1 & 5 & 3.23 & .919 & .844 & -.117 .135 & $5-.317 .269$ \\
\hline Neuroticism & 326 & 1 & 5 & 3.11 & .951 & .905 & -.170 .1 & $5-.373 .269$ \\
\hline Openness & 326 & 1 & 5 & 3.56 & .888 & .789 & -.258 .135 & $5-.297 .269$ \\
\hline Social values & 326 & 1.67 & 7 & 4.74 & 1.186 & 1.407 & -.120.135 & $5-.575 .269$ \\
\hline Personal values & 326 & 1.33 & 7 & 5.26 & 1.085 & 1.178 & -.920. 135 & $\begin{array}{lll}5.689 & .269\end{array}$ \\
\hline Individual values & 326 & 1.50 & 7 & 4.16 & 1.228 & 1.508 & $.060 \quad .135$ & $5-.623 .270$ \\
\hline
\end{tabular}


Table 2.

Aggressor profile

\begin{tabular}{lcccccccccc}
\hline & $\mathrm{N}$ & Min & Max & M & SD & \multicolumn{2}{c}{ Variance } & \multicolumn{2}{l}{ Skewness } & \multicolumn{2}{l}{ Kurtosis } \\
\hline Proactive Aggression & 45 & 1 & 3 & 1.40 & .379 & .144 & 1.181 & .354 & .813 & .695 \\
Reactive Aggression & 45 & 1 & 3 & 1.90 & .376 & .141 & .081 & .354 & .098 & .695 \\
Aggression Bullying & 45 & 1 & 5 & 2.18 & .812 & .660 & 1.891 & .354 & 3.636 & .695 \\
Victimization & 45 & 1 & 2 & 1.32 & .318 & .101 & 1.008 & .354 & -.007 & .695 \\
Bullying & 4 & & & & & & & & & \\
Self-esteem & 45 & 2 & 3 & 2.33 & .234 & .055 & .483 & .354 & -.002 & .695 \\
Extraversion & 45 & 2 & 5 & 3.90 & .975 & .950 & -.630 & .354 & -.280 & .695 \\
Agreeableness & 45 & 2 & 5 & 3.51 & .780 & .608 & .112 & .354 & -.638 & .695 \\
Conscientiousness & 45 & 1 & 5 & 3.02 & .994 & .988 & .063 & .354 & -.154 & .695 \\
Neuroticism & 45 & 1 & 5 & 3.13 & 1.115 & 1.243 & -.339 & .354 & -.539 & .695 \\
Openness & 45 & 2 & 5 & 3.53 & .944 & .891 & -.355 & .354 & -.386 & .695 \\
Social values & 45 & 1.89 & 6.78 & 4.3877 & 1.200 & 1.442 & -.103 & .354 & -.356 & .695 \\
Personal values & 45 & 1.78 & 6.56 & 5.2198 & 1.125 & 1.267 & -1.552 & .354 & 2.569 & .695 \\
Individual values & 45 & 2.67 & 6.33 & 4.4630 & 1.018 & 1.036 & .079 & .354 & -1.057 & .695 \\
\hline
\end{tabular}

Table 3.

Victim profile

\begin{tabular}{|c|c|c|c|c|c|c|c|}
\hline & $\mathrm{N}$ Min & Max & $\mathrm{M}$ & SD & Variance & Skewness & tosis \\
\hline Aggression Proactive & 541 & 2 & 1.22 & .287 & .082 & 2.096 .3274 .312 & .644 \\
\hline Aggression Reactive & 54 & 2 & 1.71 & .379 & .144 & $\begin{array}{lll}.464 & .327 & -.318\end{array}$ & .644 \\
\hline Aggression Bullying & 54 & 2 & 1.35 & .223 & .050 & .621 .3251 .036 & .639 \\
\hline Victimization Bullying & 54 & 5 & 2.26 & .637 & .406 & 1.713 .3255 .095 & .639 \\
\hline Self-esteem & 54 & 3 & 2.40 & .345 & .119 & -.975 .3252 .334 & .639 \\
\hline Extraversion & 54 & 5 & 3.32 & .942 & .888 & $-.169 .325-.291$ & .639 \\
\hline Agreeableness & 54 & 5 & 3.60 & .773 & .598 & $-.132 .325-.394$ & .639 \\
\hline Conscientiousness & 54 & 5 & 3.41 & .901 & .812 & $-.716 .325 \quad .532$ & .639 \\
\hline Neuroticism & 54 & 5 & 3.04 & .966 & .933 & $.201 \quad .325-.679$ & .639 \\
\hline Openness & $54 \quad 1$ & 5 & 3.94 & .917 & .840 & $\begin{array}{llll} & .660 & .325\end{array}$ & .639 \\
\hline Social values & 541.89 & 7 & 4.60 & 1.241 & 1.542 & $-.040 .325-.383$ & .639 \\
\hline Personal values & 542.33 & 7 & 5.23 & 1.237 & 1.532 & $-.791 .325-.113$ & .639 \\
\hline Individual values & 542.00 & 6.83 & 4.17 & 1.357 & 1.843 & $\begin{array}{lll}.230 & .327 & -.906 \\
\end{array}$ & .644 \\
\hline
\end{tabular}


12 Jara, Casas \& Ortega-Ruiz-Aggressive Behaviour

Table 4.

Bully-victim profile

\begin{tabular}{|c|c|c|c|c|c|c|c|c|}
\hline & $\mathrm{N}$ & Min & $\operatorname{Max}$ & $\mathrm{M}$ & SD & Variance & Skewness & Kurtosis \\
\hline Aggression Proactive & 12 & 1 & 3 & 1.47 & .444 & .198 & 1.560 .637 & 2.8121 .232 \\
\hline $\begin{array}{l}\text { Aggression } \\
\text { Reactive }\end{array}$ & 12 & 1 & 3 & 1.93 & .349 & .122 & 1.019 .637 & 1.3241 .232 \\
\hline $\begin{array}{l}\text { Aggression } \\
\text { Bullying }\end{array}$ & 12 & 1 & 5 & 2.90 & 1.211 & 1.467 & .354 .637 & -1.0471 .232 \\
\hline Victimization Bullying & 12 & 1 & 2 & 1.27 & .276 & .076 & 1.144 .637 & .6631 .232 \\
\hline elf-e & 12 & 2 & 3 & 2.36 & .248 & .062 & .482 .637 & 1.6101 .232 \\
\hline xtra & 12 & 3 & 5 & 4.38 & .678 & .460 & -.770 .637 & -.3261 .232 \\
\hline Agre & 12 & 2 & 4 & 3.08 & .597 & .356 & .007 .637 & -.2031 .232 \\
\hline ons & 12 & 1 & 5 & 2.54 & 1.270 & 1.612 & .608 .637 & -.4331 .232 \\
\hline Neuroticism & 12 & 1 & 5 & 2.88 & 1.316 & 1.733 & -.034 .637 & $-.981 \quad 1.232$ \\
\hline Openn & 12 & 3 & 5 & 3.96 & .722 & .521 & .389 .637 & -.9251 .232 \\
\hline Social values & 121 & 1.8 & & 3.86 & 1.346 & 1.812 & -.075 .637 & $.073 \quad 1.232$ \\
\hline Personal values & 121 & & & 4.64 & 1.633 & 2.669 & -1.054 .637 & -.3931 .232 \\
\hline Individual values & 122 & & & 4.63 & 1.195 & 1.428 & -.247 .637 & -1.1811 .232 \\
\hline
\end{tabular}

With regard to the second research objective, we performed four structural equation models (see Figures 1, 2, 3 and 4) to analyze the influence of the variables that capture personality, self-esteem and values with respect to the two major dimensions considered in the study, proactive and reactive aggression. To this end, we considered the division between involvement and non-involvement in bullying as previously explained. The calculated models are composed of nine types of observable variables (extraversion, agreeableness, conscientiousness, neuroticism, openness to experience, self-esteem, personal values, social values and individual values) and factors of proactive and reactive aggression.

Those scoring 2 or less on the victimization items and 3 or more on the aggression items were considered aggressors, while those scoring 2 or more on both the bullying and the aggression scale were considered both aggressors and victims of other aggressors (bully-victims). Those classified as victims scored 2 or less on the aggression items of the bullying scale and 
3 or more on the victimization items. The results of the analyses reveal that a significant number of subjects are involved in three distinct bullying roles. Moreover, the aggressors outnumber the victims in both types of aggression studied, while the bully-victims show the highest mean scores in terms of both aggressive behavior and bullying.

The first model calculated with those not involved in bullying using proactive aggression as the dependent variable shows an acceptable fit in line with $\mathrm{Hu}$ and Bentler (1999). The multivariate normality coefficient shows a value of 215.66. The following results were obtained for the goodness-of-fit indices: $\chi^{2}=2844.59 ; \mathrm{DF}=1076 ; \chi 2 / \mathrm{df}=2.64 ; p=.000$; $\mathrm{CFI}=.96 ; \mathrm{NNFI}=.95 ; \mathrm{IFI}=.962$ and $\mathrm{RMSEA}=.062$, thus predicting $36 \%$ of the variance of the dependent variable.

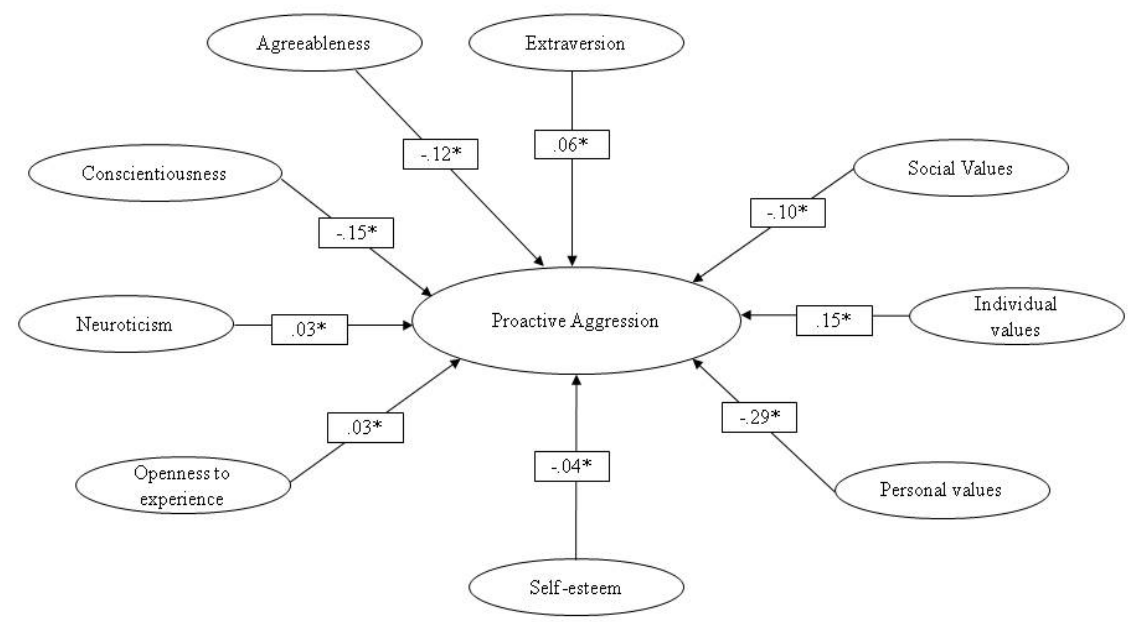

Figure 1. Structural equation model for proactive aggression (non-involvement) using personality, values and self-esteem variables. 


\section{Jara, Casas \& Ortega-Ruiz-Aggressive Behaviour}

The second model was calculated with those involved in bullying using proactive aggression as a dependent variable. As above, the model shows an acceptable fit. The multivariate normality coefficient shows a value of 96.37 . The results of the goodness-of-fit indices were as follows: $\chi 2=2853.52$; $\mathrm{DF}=1128 ; \chi 2 / \mathrm{df}=2.52 ; p=.000 ; \mathrm{CFI}=.92 ; \mathrm{NNFI}=.93 ; \mathrm{IFI}=.929$ and RMSEA $=.062$, thus predicting $30.3 \%$ of the variance of the dependent variable.

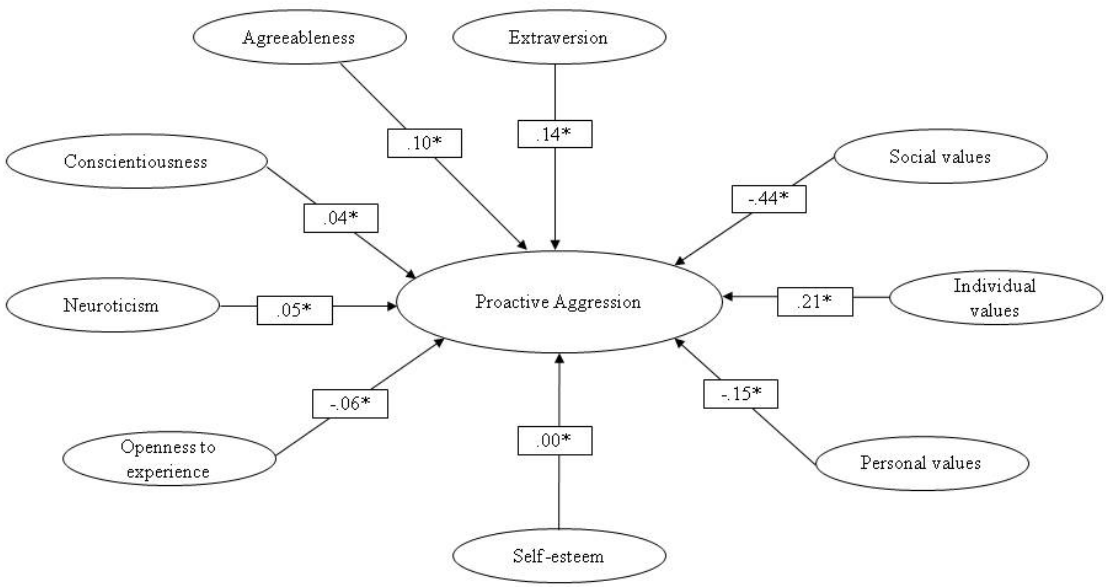

Figure 2. Structural equation model for proactive aggression (involvement) using personality, values, and self-esteem variables.

The third model was calculated with those not involved in bullying using reactive aggression as a dependent variable and shows an acceptable fit, subject to the same considerations. The multivariate normality coefficient shows a value of 1169.30 . And the adjustment indices yield the following results $\chi^{2}=3254.57 ; \mathrm{DF}=1171 ; \chi^{2} / \mathrm{df}=2.77 ; p=.000 ; \mathrm{CFI}=.98 ; \mathrm{NNFI}=$ 
.96 ; IFI $=.986$ and RMSEA $=.064$, thus predicting $33 \%$ of the variance of the dependent variable.

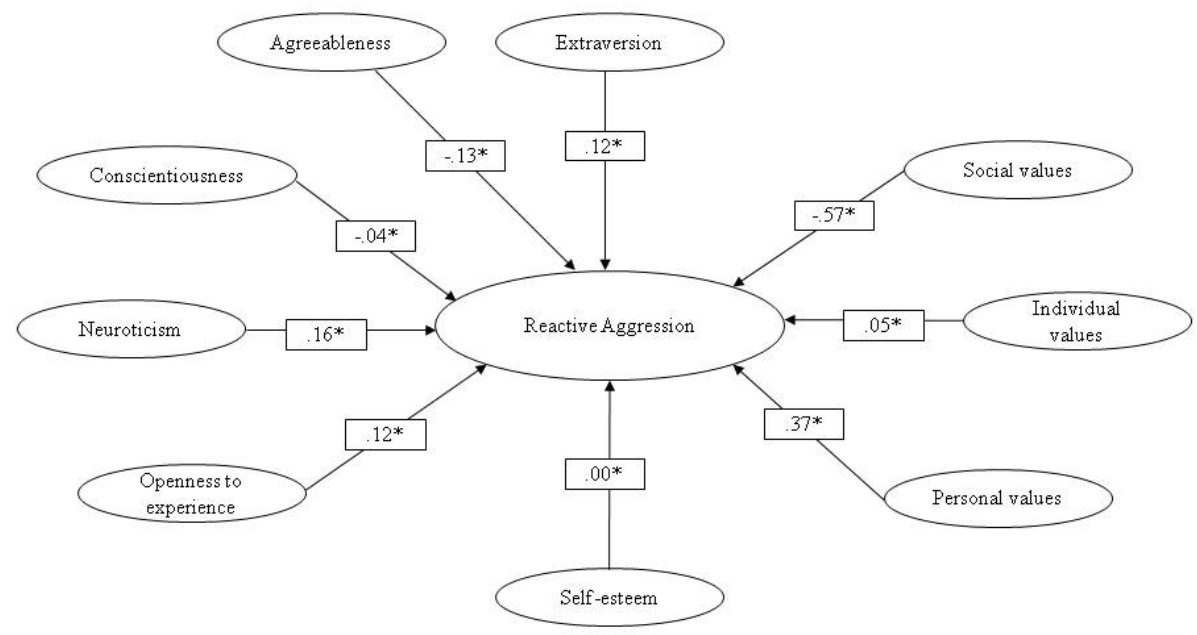

Figure 3. Structural equation model for reactive aggression (non-involvement) using personality, values, and self-esteem variables.

The fourth model was calculated with those involved in bullying using reactive aggression as the dependent variable. As above, the model shows an acceptable fit. The multivariate normality coefficient shows a value of 56.43 . The goodness-of-fit indices yielded the following results: $\chi 2=2132.32$; $\mathrm{DF}=1171 ; \chi 2 / \mathrm{df}=1.82 ; p=.000 ; \mathrm{CFI}=.92 ; \mathrm{NNFI}=.93 ; \mathrm{IFI}=.929$ and $\operatorname{RMSEA}=.074$, thus predicting $54 \%$ of the variance of the dependent variable. 


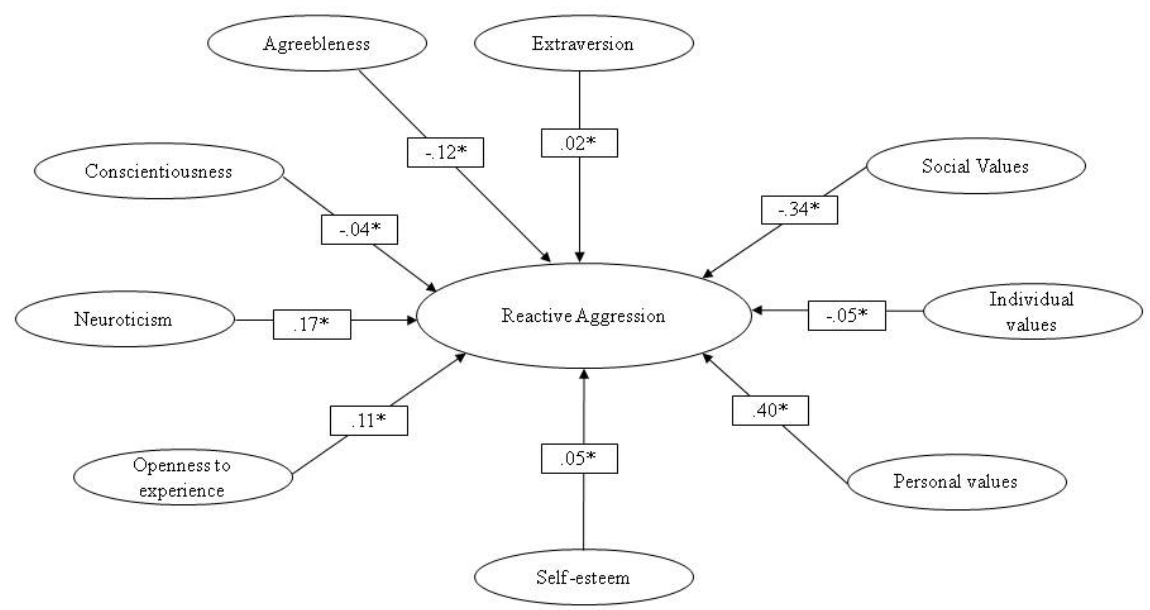

Figure 4. Structural equation model for reactive aggression (involvement) using personality, values, and self-esteem variables.

Regarding the relationships between the variables and the different types of aggression (see figures 1, 2, 3 and 4), the standardized regression coefficients show that the nine variables exert a direct effect on all four models. According to the predictive power of the variables in the models, it is important to highlight the following. In the second model (proactive aggression with bullying involvement), social values show a negative relationship with aggression $(\beta=-.44 ; p<.05)$ in contrast to individual values, which show a direct and significant relationship with aggression $(\beta=.21 ; p<.05)$. In the first model (proactive aggression with no bullying involvement), personal values are negatively related to proactive aggression $(\beta=.29 ; p<.05)$, while individual values have a direct and positive relationship with aggression $(\beta=.15 ; p<.05)$. As regards the fourth model (reactive aggression with bullying involvement), social values have an inverse relationship with reactive aggression $(\beta=.57 ; p<.05)$, while personal values have a direct and positive relationship $(\beta=.37 ; p<.05)$. As regards the third model (reactive aggression with no bullying involvement), social values have an inverse relationship $(\beta=.34 ; p<.05)$ and personal 
values have a positive relationship with reactive aggression $(\beta=.40$; $p<.05)$.

\section{Discussion and Conclusions}

The first objective of this study was to determine the level of involvement in bullying in a sample of adolescents, the percentages of aggressors, victims and bully-victims in the sample and the proactive and the reactive aggressive behavior patterns that are involved. The results reveal that a considerable number of participants were involved in bullying. In line with the literature review, personality is a factor to be considered in individual aggressiveness as it influences the level of involvement in violence in schools and hence in bullying (Massa, 2004). From a cognitive perspective, aggressors involved in bullying display a more complex personality, as do bully-victims. Victims do not exhibit a defined pattern of behavior but their personal traits are different from those of bully-victims and aggressors. These conclusions coincide with other studies showing that aggressors and victims have different personality traits (Ortega, 2010). The results of this study support several other studies which demonstrate that both proactive and reactive aggression is linked to the most basic traits of personality types.

The relationship between the personality variable and proactive aggression highlights that the participants not involved in bullying are more ethically conscientious and socially more agreeable. Taking into account these two variables and the subjects involved in proactive aggression, we found a difference in ethical conscientiousness: for those not involved in bullying ethical conscientiousness is a protective factor, while for those involved in bullying it is a risk factor. This result is significant and provides further evidence to support the widely studied personality of the aggressor in terms of what differentiates those involved in bullying from those who are not. The difference has to do with aspects of personality related to moral criteria, confirming to what extent bullying is a problem of immorality in unjustified aggressive behavior, as argued by Ortega (2010).

Regarding the relationship between personality and reactive aggression, the results for those not involved in bullying are significant given that neuroticism is a very significant risk factor. In other words, the reactive 


\section{Jara, Casas \& Ortega-Ruiz-Aggressive Behaviour}

aggressive behavior pattern is closely associated with displaying certain neurotic personality traits. Extraversion is also a variable that strongly influences involvement or non-involvement in this type of aggression, as is openness to experience or an open mentality. Those involved in bullying showed a higher score on the reactive aggression scale for neuroticism and openness to experience. This finding is of major significance given that differences were also found between proactive and reactive aggression in terms of personality. Specifically, for those involved in proactive aggression, agreeableness is a protective factor, while for those involved in reactive aggression it is a significant risk factor (Pailing et al., 2014; Rammstedt \& John, 2007).

These values bring to light very important results taking into account the three profiles of involvement in bullying (aggressors, bully-victims and victims) and enable reaching meaningful conclusions in this line of research. Social values are more important for aggressors, and although this level of importance does not differ much from that of victims, it does differ from bully-victims who score less on the scale. In other words, on the whole, aggressors involved in bullying attach more importance to society and this is highlighted both in their personal characteristics and the importance they give to social values. Personal values are important for both aggressors and victims, but are less important for bully-victims. This may suggest that the greater the involvement in bullying, the less importance is given to personal values in general. Finally, individual values showed higher scores for aggressors, lower scores for victims and the lowest scores for bully-victims. These differences between the three profiles regarding the importance of personal and social values are supported by the findings of Erikson and Schwartz, who argue that moral criteria differ according to the level of involvement in aggressive acts (Erikson, 1968; Schwartz \& Boehnke, 2004).

As regards the second objective, to determine the impact of the variables personality, values and self-esteem, this study has shown that the variables support the initial hypothesis. A significant relationship was found between the variables of personality, self-esteem and values and the two aggressive behavior patterns in relation to involvement and non-involvement in bullying and are therefore in consonance with the ideas of Salmivalli and Nieminen (2002). 
The personality variables remained more or less stable in victims and aggressors. When compared, it can be seen that extraversion is greater in aggressors, as opposed to ethical conscientiousness, which appears to be more latent in victims. In bully-victims who do not exhibit a homogeneous personality pattern, something which is more akin to the personality of victims, ethical conscientiousness is not stable. In relation to self-esteem, the aggressors show the highest rates. This is based on the previous hypothesis that there are contradictory aspects with respect to self-esteem, especially in the case of aggressors (Marsh et al., 2001; McCarthy \& Hoge, 1984). Indeed, in terms of self-esteem there are no major differences between the patterns of proactive and reactive aggression, which leads us to believe that determinant variables other than self-esteem are involved in differentiating proactive and reactive patterns of aggressive behavior. In other words, perhaps this result indicates, as many studies argue, that although selfesteem is an important factor to consider, there may be other personal variables and ethical components of personality that override this selfevaluative factor. It may also indicate a weakness of the study, such as the small sample size and small number of subjects involved in aggressive behavior of one type or another, which does not allow for a more precise approximation of the role that self-esteem plays in discriminating the greater or lesser impact of being or not being a bullying aggressor.

Especially relevant in this study is that the results of the models predict aggression in relation to the variables, both for personality and the specific assessment tool used to measure social and moral values. Specifically, this study shows that there is a relationship between involvement and noninvolvement in bullying and individual, personal and social values. The results for those involved in bullying highlight that social values are a determining factor in proactive aggression. In other words, social values significantly decrease the likelihood of proactive aggression. In statistical terms, the results indicate that personal values have a positive impact on proactive aggression. When personal values obtain a higher score, aggression increases, thus suggesting that higher scores in personal values and lower ones in social values - lead to a greater likelihood of aggression. Something quite similar can be observed in terms of those involved in 


\section{Jara, Casas \& Ortega-Ruiz-Aggressive Behaviour}

reactive aggression; it seems that individual ethics versus more social ethics is determinant in terms of both proactive and reactive aggressive behavior.

Those not involved in bullying also present interesting results regarding personal and social values. The results indicate that social values cause proactive aggression to decrease, in other words, they act as a protective factor. In contract, a high individual values score has a totally opposite effect, in other words, a personal and perhaps egocentric vision acts as a risk factor. Conversely, for those not involved in bullying, the results clearly shown that social values and personal values also have a decisive impact on reactive aggression. Specifically, the former decrease and the latter increase the likelihood of reactive aggression. Taking into account these results and in relation to the above research, it seems evident that values are determinant variables whose presence modulates patterns of proactive and reactive aggressive behavior in those involved and not involved in bullying (Erikson, 1968; Hofstede, 1980; Oliva, 2011; Triandis, Bontempo, Villareal, Asai, \& Lucca, 1988).

We can confirm that the findings of this study corroborate the fact that the variables relating to personal and social values are also related to proactive and reactive aggression in bullying, both for involvement and noninvolvement, regardless of the way adolescents become involved: either as aggressors with a greater tendency to exhibit proactive aggression or as victims with a greater tendency for reactive aggressive behavior.

Given the significant role we must attribute to moral (personal) and ethical (social) values and to the differential nuances of both highlighted in the assessment tools used, the ethical dimension in its two facets - the more personal and perhaps individualistic facet and the more social facet that may be more closely related to moral criteria - must be studied in greater depth with better assessment tools. However, these limitations do not veil the scope of this study on aggressive behavior in bullying when adopting a perspective that differentiates its two major patterns: proactive and reactive aggressive behavior. 


\section{References}

Bandura, A. (1973). Aggression: A social learning analysis. Prentice-Hall. Retrieved from http://psycnet.apa.org/psycinfo/1974-00914-000

Bandura, A. (1999). Social cognitive theory of personality. Handbook of Personality: Theory and Research, 154-196.

Caprara, G. V., \& Pastorelli, C. (1993). Early emotional instability, prosocial behaviour, and aggression: Some methodological aspects. European Journal of Personality, 7(1), 19-36.

Cerezo, F. (2002). El bullying y su relación con las actitudes de socialización en una muestra de adolescentes. Revista Electrónica Interuniversitaria de Formación Del Profesorado, 5(1), 10-16.

Crick, N. R., \& Dodge, K. A. (1996). Social information-processing mechanisms in reactive and proactive aggression. Child Development, 67(3), 993-1002.

Del Barrio, C., Martín, E., Almeida, A., \& Barrios, Á. (2003). Del maltrato y otros conceptos relacionados con la agresión entre escolares, y su estudio psicológico. Infancia Y Aprendizaje, 26(1), 9-24.

Dodge, K. A., \& Coie, J. D. (1987). Social-information-processing factors in reactive and proactive aggression in children's peer groups. Journal of Personality and Social Psychology, 53(6), 1146.

Dodge, K. A., \& Schwartz, D. (1997). Social information processing mechanisms in aggressive behavior. Retrieved from http://psycnet.apa.org/psycinfo/1997-36421-017

Erikson, E. H. (1968). Youth and crisis. WW Norton\&Company, New YorkLondon, 17.

Flora, D. B., \& Curran, P. J. (2004). An empirical evaluation of alternative methods of estimation for confirmatory factor analysis with ordinal data. Psychological Methods, 9(4), 466. doi:10.1037/1082989X.9.4.466

Hart, D., Hofmann, V., Edelstein, W., \& Keller, M. (1997). The relation of childhood personality types to adolescent behavior and development: A longitudinal study of Icelandic children. Developmental Psychology, 33(2), 195. 


\section{Jara, Casas \& Ortega-Ruiz-Aggressive Behaviour}

Hofstede, G. (1980). Angola coffee-Or the confrontation of an organization with changing values in its environment. Organization Studies, 1(1), 21-40.

Hu, L., \& Bentler, P. M. (1999). Cutoff criteria for fit indexes in covariance structure analysis: Conventional criteria versus new alternatives. Structural Equation Modeling: A Multidisciplinary Journal, 6(1), 155.

Marsh, H. W., Parada, R. H., Yeung, A. S., \& Healey, J. (2001). Aggressive school troublemakers and victims: a longitudinal model examining the pivotal role of self-concept. Journal of Educational Psychology, 93(2), 411.

Massa, J. L. P. (2004). Introducción: Agresión y comportamiento en la adolescencia. Monografias de Psiquiatría, 16(1), 1-20.

McCarthy, J. D., \& Hoge, D. R. (1984). The dynamics of self-esteem and delinquency. American Journal of Sociology, 396-410.

Monks, C., \& Ruiz, R. O. (2005). Agresividad injustificada entre preescolares. Psicothema, 17(3), 453-458.

Oliva, A. (2011). Desarrollo positivo adolescente y los activos que lo promueven: un estudio en centros docentes andaluces. Junta de Andalucía, Secretaría General de Salud Pública y Participación.

Olweus, D. (1993). Bullying at school: what we know and what we can do. Oxford, UK; Cambridge, USA: Blackwell.

Ortega, R. (2010). Agresividad injustificada, bullying y violencia escolar. Madrid: Alianza Editorial.

Ortega, R., \& Mora-Merchán, J. A. (2008). Las redes de iguales y el fenómeno del acoso escolar: explorando el esquema dominiosumisión. Infancia Y Aprendizaje, 31(4), 515-528. doi: 10.1174/021037008786140922

Ortega-Ruiz, R., Del Rey, R., \& Casas, J. A. (2016). Evaluar el bullying y el cyberbullying validación española del EBIP-Q y del ECIP-Q. Psicología Educativa, 22(1), 71-79. doi:10.1016/j.pse.2016.01.004

Ortega-Ruiz, R., Sánchez, V., \& Menesini, E. (2002). Violencia entre iguales y desconexión moral: un análisis transcultural. Psicothema, 14(1), 37-49. 
Pailing, A., Boon, J., \& Egan, V. (2014). Personality, the Dark Triad and violence. Personality and Individual Differences, 67, 81-86. doi:10.1016/j.paid.2013.11.018

Pellegrini, A. D., Bartini, M., \& Brooks, F. (1999). School bullies, victims, and aggressive victims: factors relating to group affiliation and victimization in early adolescence. Journal of Educational Psychology, 91(2), 216.

Poulin, F., \& Boivin, M. (1999). Proactive and reactive aggression and boys' friendship quality in mainstream classrooms. Journal of Emotional and Behavioral Disorders, 7(3), 168-177.

Poulin, F., \& Boivin, M. (2000). Reactive and proactive aggression: Evidence of a two-factor model. Psychological Assessment, 12(2), 115-122. http://doi.org/10.1037/1040-3590.12.2.115

Pullmann, H., \& Allik, J. (2000). The Rosenberg Self-Esteem Scale: its dimensionality, stability and personality correlates in Estonian. Personality and Individual Differences, 28(4), 701-715. https://doi.org/10.1016/S0191-8869(99)00132-4

Raine, A., Dodge, K., Loeber, R., Gatzke-Kopp, L., Lynam, D., Reynolds, C., ... Liu, J. (2006). The reactive-proactive aggression questionnaire: differential correlates of reactive and proactive aggression in adolescent boys. Aggressive Behavior, 32(2), 159-171. doi:10.1002/ab.20115

Rammstedt, B., \& John, O. P. (2007). Measuring personality in one minute or less: A 10-item short version of the Big Five Inventory in English and German. Journal of Research in Personality, 41(1), 203-212. doi:10.1016/j.jrp.2006.02.001

Rutter, M., Giller, H., \& Hagell, A. (2000). La conducta antisocial de los jóvenes. Retrieved from http://dialnet.unirioja.es/servlet/libro?codigo $=228964$

Salmivalli, C., \& Nieminen, E. (2002). Proactive and reactive aggression among school bullies, victims, and bully-victims. Aggressive Behavior, 28(1), 30-44. doi:10.1002/ab.90004

Samper, P., Tur, A. M., Mestre, V., \& Cortés, M. T. (2008). Agresividad y afrontamiento en la adolescencia. Una perspectiva intercultural. 
24 Jara, Casas \& Ortega-Ruiz-Aggressive Behaviour

International Journal of Psychology and Psychological Therapy, 8(3), 431-440.

Schwartz, S. H., \& Boehnke, K. (2004). Evaluating the structure of human values with confirmatory factor analysis. Journal of Research in Personality, 38(3), 230-255. doi:10.1016/S0092-6566(03)00069-2

Stoudt, B. G. (2006). "You're Either In or You're Out" School Violence, Peer Discipline, and the (Re) Production of Hegemonic Masculinity. Men and Masculinities, 8(3), 273-287. doi:10.1177/1097184X05282070

Triandis, H. C., Bontempo, R., Villareal, M. J., Asai, M., \& Lucca, N. (1988). Individualism and collectivism: Cross-cultural perspectives on self-ingroup relationships. Journal of Personality and Social Psychology, 54(2), 323.

Xu, Y., Raine, A., Yu, L., \& Krieg, A. (2014). Resting heart rate, vagal tone, and reactive and proactive aggression in Chinese children. Journal of Abnormal Child Psychology, 42(3), 501-514. doi:10.1007/s10802013-9792-2

Zych, I., Ortega-Ruiz, R., \& Del Rey, R. (2015). Scientific research on bullying and cyberbullying: Where have we been and where are we going. Aggression and Violent Behavior, 24, 188-198. doi:10.1016/j.avb.2015.05.015

Natalia Jara is PhD student in the department of psychology at the University of Cordoba

Jose Antonio Casas is Assistant professor of the Department of Psychology of the University of Cordoba

Rosario Ortega-Ruiz is Full Professor of the Department of Psychology at the University of Cordoba

Contact Address: Avda. San Alberto Magno S/N 14004 Cordoba (Spain) 
Instructions for authors, subscriptions and further details:

http://ijep.hipatiapress.com

\section{A Cross-Cultural Validation of the MUSIC ${ }^{\circledR}$ Model of Academic Motivation Inventory: Evidence from Chinese- and Spanish- Speaking University Students}

Brett D. Jones ${ }^{1}$, Ming $\mathrm{Li}^{2}$, and Juan M. Cruz ${ }^{3}$

1) Virginia Tech, U.S.

2) Sias International University, China

3) Universidad Javeriana, Colombia

Date of publication: February $24^{\text {th }}, 2017$

Edition period: February 2017 - June 2017

To cite this article: Jones, B. D., Li, M., \& Cruz, J. M. (2017). A CrossCultural Validation of the MUSIC ${ }^{\circledR}$ Model of Academic Motivation Inventory: Evidence from Chinese- and Spanish-Speaking University Students. International Journal of Educational Psychology, 6(1), 25-44. doi: 10.17583/ijep.2017.2357

To link this article: http://dx.doi.org/10.17583/ijep.2017.2357

PLEASE SCROLL DOWN FOR ARTICLE

The terms and conditions of use are related to the Open Journal System and to Creative Commons Attribution License (CC-BY). 


\section{A Cross-Cultural Validation of the MUSIC ${ }^{\circledR}$ Model of Academic Motivation Inventory: Evidence from Chinese- and Spanish-Speaking University Students}

Brett D. Jones

Virginia Tech
Ming Li

Sias International University
Juan M. Cruz

Universidad Javeriana

\section{Abstract}

The purpose of this study was to examine the extent to which Chinese and Spanish translations of the College Student version of the MUSIC ${ }^{\circledR}$ Model of Academic Motivation Inventory (MUSIC Inventory; Jones, 2012) demonstrate acceptable psychometric properties. We surveyed 300 students at a university in China and 201 students at a university in Colombia using versions of the MUSIC Inventory that were translated into Chinese and Spanish, respectively. To assess the psychometric properties of the inventory, we examined: (a) the internal consistency reliabilities for all of the scales, (b) the fit indices and factor loadings produced from confirmatory factor analysis, and (c) correlations between the MUSIC Inventory scales and behavioral and cognitive engagement. The results provide evidence that the Chinese and Spanish translations of the MUSIC Inventory demonstrate acceptable psychometric properties for use with undergraduate students. Therefore, instructors and researchers can use the translated inventories to assess students' perceptions of the five MUSIC ${ }^{\circledR}$ Model of Motivation components.

Keywords: MUSIC Model of Motivation, motivation, engagement, assessment, motivating students 


\section{Validación Transcultural del Cuestionario del Modelo de Motivación Académica}

\section{MUSIC $^{\circledR}$ : Evidencia proveniente de Estudiantes Universitarios de} Habla Hispana y China

\author{
Brett D. Jones \\ Virginia Tech
}

\author{
Ming Li \\ Sias International University
}

\author{
Juan M. Cruz \\ Universidad Javeriana
}

\section{Resumen}

El propósito de este estudio era determinar en qué medida se cumplían las propiedades sicométricas de las traducciones al dhino y al español de la versión para estudiantes universitarios del cuestionario de motivación académica MUSIC (MUSIC Inventory; Jones, 2012). Encuestamos 300 estudiantes de una universidad en China y 201 estudiantes de una universidad en Colombia usando versiones del cuestionario MUSIC traducidas al chino y al español, respectivamente. Para medir las propiedades sicométricas del cuestionario, examinamos: a) La confiabilidad de consistencia interna para todas las escalas b) los índices de ajuste y peso de los factores producidos a partir de un análisis factorial confirmatorio, y (c) las correlaciones entre las escalas del cuestionario MUSIC y el involucramiento conductual y cognitivo. Los resultados proveen evidencia que tanto las traducciones al chino como al español del cuestionario MUSIC demuestran aceptables propiedades sicométricas para su uso con estudiantes de pregrado. Por tanto, profesores e investigadores pueden usar los cuestionarios para medir las percepciones de los estudiantes de los 5 componentes del modelo de motivación académica MUSIC.

Palabras clave: Modelo de motivación académica MUSIC, involucramiento, evaluación, motivación de estudiantes 
The MUSIC ${ }^{\circledR}$ Model of Motivation (abbreviated as the "MUSIC
model"; Jones, 2009, 2015) is a multidimensional model that
instructors can use to design courses to engage students in learning. The MUSIC model was developed to help teachers apply current research and theories related to motivation and engagement. The basic principles of the MUSIC model are that the instructor needs to ensure that students: (1) feel eMpowered by having the ability to make decisions about some aspects of their learning, (2) understand why what they are learning is Useful for their short- or long-term goals, (3) believe that they can Succeed if they put forth the effort required, (4) are Interested in the content and instructional activities, and (5) believe that the instructor and others in the learning environment Care about their learning and about them as a person (MUSIC is an acronym for these principles; Jones, 2009, 2015). Thus, the MUSIC model is an organizational framework for instructional strategies that teachers can use to motivate and engage students.

Empirical studies have documented that the MUSIC model components are distinct constructs in samples of undergraduate students (Jones, Osborne, Paretti, \& Matusovich, 2014; Jones \& Skaggs, 2016; Jones, Tendhar, \& Paretti, 2015; Jones \& Wilkins, 2013). In addition, the MUSIC model components have been shown to predict aspects of students' motivation and engagement (Jones, 2010; Jones et al., 2014; Jones et al., 2015). For example, Jones (2010) found that the course format (face-to-face or online) and gender were factors that affected which components of the MUSIC model predicted students' behavioral engagement.

The MUSIC model can be used in several ways to help teachers improve their instruction. For example, after instruction has occurred (e.g., an instructional activity, a class, a course), it can be helpful for instructors to assess how students perceived the instruction related to each of the five MUSIC model components. Instructors can then use this feedback to improve their course by redesigning it (Jones, 2015). To assess students' perceptions of the MUSIC components, it is necessary to measure students' perceptions. One means to accomplish this is to ask students to complete a self-report questionnaire with items related to each of the MUSIC model components. To do this, some researchers have pieced together scales from various instruments to assess students' perceptions of the MUSIC model 


\section{Jones-Validation of the MUSIC Model}

components after instruction (e.g., Jones, 2010; Jones, Epler, Mokri, Bryant, \& Paretti, 2013; Jones, Watson, Rakes, \& Akalin, 2012; McGinley \& Jones, 2014); however, using a variety of instruments is not ideal for several reasons. For example, the instruments tend to be written by different individuals at different times for different purposes. As a result, the items can vary with respect to the types of items (e.g., questions, statements), number of response options (e.g., on a Likert-format scale ranging from 1 to 5,1 to 6 , or 1 to 7 ), and the labels provided on the Likert-format response options (e.g., strongly agree, very interested). Also, the tone and style of the items can vary when the items are written by different individuals. These differences may confuse students while they are responding to the items and can make it difficult for the instructor to compare results across scales.

To address these issues, Jones (2012) developed the MUSIC ${ }^{\circledR}$ Model of Academic Motivation Inventory (abbreviated in this article as the "MUSIC Inventory") that can be used to assess students' perceptions of each of the five MUSIC model components. The MUSIC Inventory (College Student version) consists of items that are divided into five scales: empowerment, usefulness, success, interest, and caring. Students respond to the scale items using the same Likert-format options. The items in each scale are averaged to create a mean scale score.

The College Student version of the MUSIC Inventory has been shown to produce valid scores with samples of undergraduate students (Jones \& Skaggs, 2016; Tendhar, 2015). For example, Jones and Skaggs (2016) assessed undergraduate students' perceptions of many different types of courses to provide validity evidence for the use of the MUSIC Inventory with college students. They used classical item analysis, factor analysis, correlations with similar scales, and Cronbach's alpha values to demonstrate the validity of the scores produced by the MUSIC Inventory. They documented that the five-factor MUSIC model fit the data well and reported excellent Cronbach's alpha values of .91 for empowerment, .96 for usefulness, .93 for success, .95 for interest, and .93 for caring.

Because of the successful psychometric properties of the College version of the MUSIC Inventory, there was a demand for its use in other populations besides college students. Consequently, the MUSIC Inventory was modified for use with elementary school students (Jones \& Sigmon, 2016), middle and 
high school students (Jones \& Wilkins, 2015; Parkes, Jones, \& Wilkins, 2015), and professors (Jones, 2015) (see Jones, 2012, for all of the available versions). In addition, there was a demand for its use by students whose native language was not English; as a result, the MUSIC Inventory has been translated to Icelandic (Schram, 2015) and Arabic (Mohamed, Soliman, \& Jones, 2013), and has been shown to demonstrate acceptable psychometric properties.

\section{Purpose and Research Question}

Given that the College Student version of the MUSIC Inventory has been successfully translated from English to Icelandic and Arabic, we hypothesized that this version could also be translated from English to Chinese and Spanish. If the translation was successful, it would demonstrate not only the acceptable psychometric properties of the MUSIC Inventory in these languages, but it would also demonstrate that the MUSIC model is generalizable to cultures besides American (Jones \& Skaggs, 2016), Icelandic (Schram \& Jones, 2016), and Egyptian (Mohamed et al., 2013) cultures. Consequently, our primary research question was: Do Chinese and Spanish translations of the College Student version of the MUSIC Inventory demonstrate acceptable psychometric properties? If so, the translated versions of the MUSIC Inventory could be used by instructors and researchers to assess students' perceptions of the MUSIC model components. Furthermore, it would provide evidence that the MUSIC model is generalizable to at least some Chinese and Hispanic cultures. 


\section{Method}

\section{Participants}

Chinese-speaking participants. The Chinese-speaking participants included undergraduate students from a large university in central China. Students were enrolled in one of five majors within the School of Business. Of the 348 students who were invited to participate in the study, 300 students participated, yielding an $86.2 \%$ response rate. More of the students were female $(183$ students $=61.0 \%)$ than male $(117=39.0 \%)$. The majority of the participants reported that they were Han nationality $(n=296,98.7 \%)$, whereas four participants $(1.3 \%)$ reported they were one of the minority nationalities. Regarding their class standing, 75 (25.0\%) were first-year students, 97 (32.3\%) were sophomores, and 128 (42.7\%) were juniors.

Spanish-speaking participants. The Spanish-speaking participants included undergraduate students from a large university in Colombia. Students were enrolled in one of three majors within the School of Engineering. The number of Spanish-speaking participants was 201, with most students from the Electrical Engineering (EE) major $(146=72.6 \%)$ and the remaining 55 students $(27.4 \%)$ from the Systems Engineering (SI) and Industrial Engineering (IE) majors. The response rate was 25.2\% $(n=146$ out of 579) from EE and 3.1\% $(n=55$ out of 1,726) for SI and IE. One-third of the students $(67=33.3 \%)$ were female and two-thirds $134(66.7 \%)$ were male. All participants reported Colombian nationality. Participants were split across the five class standings, with 30 (14.9\%) first-year, $46(22.9 \%)$ second-year, 30 (14.9\%) third-year, 45 (22.4\%) four-year, and $50(24.9 \%)$ fifth-year students (in Colombia, the majority of engineering majors require five years to complete a degree).

\section{Procedure}

The Chinese participants completed a paper-and-pencil questionnaire in class and the Colombian students completed an online questionnaire outside of class time. The questionnaires administered in both countries were similar in that they both included items related to the instruments described in the 
next section and items assessing their demographic information (e.g., class standing, gender). Participants in both countries were asked to list a course they were currently enrolled in and to answer the questionnaire items in response to that course. The Chinese students were asked to select a course different from the one in which they were completing the questionnaire unless they were not enrolled in any other courses. In the Chinese sample, the responses represented students' perceptions in relation to 34 different face-to-face courses. In the Spanish sample, the responses represented students' perceptions in relation to 70 different face-to-face courses.

\section{Instruments}

\section{MUSIC $^{\circledR}$ Model of Academic Motivation Inventory (College Student} version). The MUSIC Inventory (College Student version) consists of 26 items that are divided into five scales: a five item empowerment scale, a five item usefulness scale, a four item success scale, a six item interest scale, and a six item caring scale (Jones, 2012). Students respond to the scale items by choosing one of six options on a Likert-format scale: 1 = Strongly disagree, 2 Disagree, 3 = Somewhat disagree, $4=$ Somewhat agree, $5=$ Agree, $6=$ Strongly agree. The items in each scale are averaged to create a mean scale score. For example, the five empowerment items are averaged to create a mean scale score for empowerment. The MUSIC Inventory has been shown to produce reliable and valid scores and to correlate with other measures as expected (Jones \& Skaggs, 2016). The complete inventory is available at Jones (2012). Example items include the following: "I have flexibility in what I am allowed to do in this course" (empowerment), "In general, the coursework is useful to me" (usefulness), "I am confident that I can succeed in the coursework" (success), "The coursework is interesting to me" (interest), and "The instructor cares about how well I do in this course" (caring).

In this study, the College Student version of the MUSIC Inventory (Jones, 2012) was translated into Chinese and Spanish. For both languages, the MUSIC Inventory was translated by an individual whose native language was the target language and who was enrolled in a doctoral degree program in a U.S. university at the time of the translation. The Chinese translator had 


\section{Jones-Validation of the MUSIC Model}

worked as a professor at a university in China for 16 years and the Spanish translator had worked as a professor at a university in Colombia for 13 years. The original translations were then translated back into English (backtranslated) by other individuals whose native language was the target language (Villagran \& Lucke, 2005). The individuals who conducted the back-translations had not seen the original English version of the MUSIC Inventory. The back-translations were then compared by an individual whose native language was English, who had worked as a professor at U.S. universities for 18 years, and who was familiar with the constructs in the MUSIC model and MUSIC Inventory. The native English speaker found only a few discrepancies in the back-translation and worked with the translator and back-translator to resolve the issues until the inventory items were deemed to be acceptable by the English speaker and the translator.

Behavioral engagement. For the Chinese sample, we used the same 4item measure of effort used by Jones (2010) that was based on the 5-item Effort/Importance scale that is part of the Intrinsic Motivation Inventory (Plant \& Ryan, 1985). This scale assesses the amount of perceived effort that students put forth in a course. Although the other engagement scales in this study include a 5-point Likert-format scale, we used a 6-point Likert-format scale $(1$ = Strongly disagree, $2=$ Disagree, 3 = Somewhat disagree, $4=$ Somewhat agree, $5=$ Agree, $6=$ Strongly agree) for this measure because it had been validated in prior studies. An example item is: "I put a lot of effort into this course." In Jones (2010), the reliability estimates across multiple samples were good $(\alpha=.84, .84, .86, .84)$.

For the Spanish sample, we used the 8-item behavioral engagement scale that is part of the engagement scale developed by Wang, Fredricks, Ye, Hofkens, and Linn (2016). They defined behavioral engagement in terms of "involvement in academic and class-based activities, presence of positive conduct, and absence of disruptive behavior" (p. 2). All items included a 5point Likert-format scale $(1=$ Not at all like me, $2=$ Not much like me, $3=$ Somewhat like me, $4=$ Mostly like me, 5 = Very much like me). An example item is: "I complete my homework on time." In Wang et. al. (2016), the alpha reliability estimate for this scale was good $(\alpha=.81)$.

Cognitive engagement. For the Chinese sample, we used the 8-item Self-Regulated Strategy Use scale that is part of the Student Perceptions of 
Classroom Knowledge-Building Scale (SPOCK; Shell \& Husman, 2008; Shell et al., 2005). The Self-Regulated Strategy Use scale assesses the extent of students' behaviors and strategies associated with self-regulation, such as of planning, goal setting, monitoring, and evaluation of studying and learning. An example item is: "I try to determine the best approach for studying each assignment." Students responded on a 5-point Likert-type scale with descriptors at each point $(1=$ Almost never, $2=$ Seldom, $3=$ Sometimes, 4 = Often, 5 = Almost always). Shell and Husman (2008) documented an acceptable reliability estimate $(\alpha=.81)$.

For the Spanish sample we used the 8-item cognitive engagement scale that is part of the engagement scale developed by Wang et. al. (2016). They defined cognitive engagement as "self-regulated learning, using deep learning strategies, and exerting the necessary cognitive strategies for the comprehension of complex ideas" (p. 2). All items included a 5-point Likertformat scale $(1=$ Not at all like me, $2=$ Not much like me, $3=$ Somewhat like me, 4 = Mostly like me, $5=$ Very much like me). An example item is: "I try to connect what I am learning to things I have learned before." In Wang et. al. (2016), the reliability estimate for this scale was $\alpha=.75$.

\section{Analysis and Interpretation of Values}

In this section, we discuss the analyses that we conducted to address our research question and to assess the psychometric properties of Chinese and Spanish translations of the College Student version of the MUSIC Inventory. First, we assessed the internal consistency reliability of both translations by calculating Cronbach's alpha values for all of the MUSIC Inventory scales using SPSS (version 23). We used the following criteria to judge the values (George \& Mallery, 2003): greater than 0.9 was excellent, between 0.8 and 0.9 was good, between 0.7 and 0.8 was acceptable, between 0.6 and 0.7 was questionable, between 0.5 and 0.6 was poor, and below 0.5 was unacceptable.

Second, to examine how the items in the MUSIC Inventory fit the fivefactor structure of the MUSIC model, we conducted confirmatory factor analyses (CFA) using LISREL (version 8.80). We used three fit indices to assess the results of the CFA: the Comparative Fit Index (CFI), the 


\section{Jones-Validation of the MUSIC Model}

Standardized Root Mean Square Residual (SRMR), and the Root Mean Square Error of Approximation (RMSEA). Although the CFI can range between 0 and 1 , values closer to 1 indicate a better fit (values above .90 represent reasonable fit and above .95 represent good fit; $\mathrm{Hu} \&$ Bentler, 1999). The SRMR also ranges from 0 and 1, but values closer to 0 indicate a better fit (less than .05 indicates good fit [Byrne, 2001] and less than .10 indicates reasonable fit [Kline, 2005]). Finally, the RMSEA can vary between 0 and 1 with values closer to 0 indicating better fit (values less than .08 indicate reasonable fit and values less than .05 indicate good fit; Browne \& Cudeck, 1993; Byrne, 2001; Kline, 2005). We also examined the factor loadings for each item on the appropriate factor (e.g., the empowerment items should load adequately on the empowerment factor). We deemed factor loadings to be acceptable if they were greater than 0.32 (Tabachnick \& Fidell, 1996).

Third, as evidence of predictive validity, we calculated Pearson's correlation coefficients using SPSS (version 23) to examine the relationships between the MUSIC Inventory components and behavioral and cognitive engagement. Given that increases in students' perceptions of the MUSIC model components should lead to greater engagement (Jones, 2009, 2015), we predicted that the MUSIC Inventory components would positively correlate with behavioral and cognitive engagement.

\section{Results}

To assess the reliability of each of the MUSIC Inventory scales, we calculated the Cronbach's alpha values shown in Table 1. The alpha values ranged from .82 to .95 , indicating that the reliability of the scales was good to excellent (George \& Mallery, 2003). As a means of comparison in Table 1, we also present the alpha values that were reported for the English version of the MUSIC Inventory in Jones and Skaggs (2016, p. 5). 
Table 1

Cronbach's Alpha Values and Fit Indices

\begin{tabular}{|c|c|c|c|c|c|c|c|c|c|}
\hline \multirow{2}{*}{$\begin{array}{l}\text { Inventory } \\
\text { version }\end{array}$} & \multirow[b]{2}{*}{$n$} & \multicolumn{5}{|c|}{ Cronbach's alpha values } & \multirow[b]{2}{*}{ CFI } & \multirow[b]{2}{*}{ SRMR } & \multirow[b]{2}{*}{ RMSEA } \\
\hline & & $\mathrm{M}$ & $\mathrm{U}$ & $\mathrm{S}$ & I & $\mathrm{C}$ & & & \\
\hline Chinese & 300 & .82 & .89 & .87 & .93 & .88 & 0.97 & 0.060 & 0.089 \\
\hline Spanish & 201 & .88 & .93 & .91 & .95 & .92 & 0.97 & 0.054 & 0.107 \\
\hline English $^{\mathrm{a}}$ & 338 & .91 & .96 & .93 & .95 & .93 & 0.92 & 0.055 & 0.085 \\
\hline
\end{tabular}

Note. CFI, RMSEA, and SRMR are values from CFAs that were conducted with all the items from the MUSIC Inventory (i.e., empowerment [M], usefulness [U], success [S], interest [I], and caring [C]) scales separately for the Chinese and Spanish translations.

${ }^{a}$ Values for the English version were reported in Jones and Skaggs (2016) and were not based on data collected in the present study.

The fit indices from the CFA results are also shown in Table 1, along with the values from the English version presented in Jones and Skaggs (2016, p. 5). For the Chinese and Spanish translations, the CFI values indicate a good fit (Hu \& Bentler, 1999), the SRMR values indicate a reasonable fit (Kline, 2005), and the RMSEA values indicate a borderline reasonable fit (Browne \& Cudeck, 1993; Byrne, 2001; Kline, 2005). The factor loadings from the CFAs (see Table 2) ranged from .60 to .91, indicating that the items loaded well on their intended factors (Tabachnick \& Fidell, 1996). 
36 Jones-Validation of the MUSIC Model

Table 2

Standardized Factor Loadings from the CFAs

\begin{tabular}{|c|c|c|c|c|c|}
\hline Item & Empowerment & Usefulness & Success & Interest & Caring \\
\hline M1 & $.75, .72$ & & & & \\
\hline M2 & $.60, .74$ & & & & \\
\hline M3 & $.66, .81$ & & & & \\
\hline M4 & $.73, .75$ & & & & \\
\hline M5 & $.73, .83$ & & & & \\
\hline U1 & & $.81, .88$ & & & \\
\hline $\mathrm{U} 2$ & & $.72, .86$ & & & \\
\hline U3 & & $.80, .86$ & & & \\
\hline U4 & & $.80, .84$ & & & \\
\hline U5 & & $.79, .81$ & & & \\
\hline $\mathrm{S} 1$ & & & $.81, .85$ & & \\
\hline S2 & & & $.81, .88$ & & \\
\hline S3 & & & $.81, .87$ & & \\
\hline S4 & & & $.76, .82$ & & \\
\hline $\mathrm{I} 1$ & & & & $.85, .82$ & \\
\hline $\mathrm{I} 2$ & & & & $.86, .87$ & \\
\hline $\mathrm{I} 3$ & & & & $.82, .91$ & \\
\hline I4 & & & & $.86, .90$ & \\
\hline I5 & & & & $.78, .89$ & \\
\hline I6 & & & & $.80, .86$ & \\
\hline $\mathrm{C} 1$ & & & & & $.69, .78$ \\
\hline $\mathrm{C} 2$ & & & & & $.80, .85$ \\
\hline C3 & & & & & $.61, .84$ \\
\hline $\mathrm{C} 4$ & & & & & $.75, .75$ \\
\hline $\mathrm{C} 5$ & & & & & $.80, .85$ \\
\hline $\mathrm{C} 6$ & & & & & $.80, .79$ \\
\hline
\end{tabular}

Note. The two numbers in each cell are the standardized coefficients from two different analyses. The first number represents the Chinese sample and the second number represents the Spanish sample. 
To examine the predictive validity of the scores produced by the MUSIC Inventory, we correlated the MUSIC constructs with behavioral and cognitive engagement. The correlation coefficients ranged from .28 to .61, which indicated a moderate correlation between the MUSIC components and engagement (see Table 3). Note that the instruments used to measure engagement in the Chinese sample were different from the instruments used with the Spanish sample; thus, some of the variation in the correlations could be attributed to the differences in the measures.

\section{Table 3}

Pearson's Correlation Coefficients for the Study Constructs

\begin{tabular}{lccccc}
\hline Engagement & Empowerment & Usefulness & Success & Interest & Caring \\
\hline Behavioral & $.57, .41$ & $.61, .40$ & $.61, .37$ & $.61, .43$ & $.52, .28$ \\
Cognitive & $.45, .40$ & $.48, .38$ & $.54, .36$ & $.43, .40$ & $.37, .31$ \\
\hline
\end{tabular}

Notes. $p \leq .001$ for all coefficients. The first number in each cell represents the Chinese sample and the second number represents the Spanish sample.

\section{Discussion}

The primary purpose of this study was to determine the extent to which Chinese and Spanish translations of the College Student version of the MUSIC Inventory demonstrated acceptable psychometric properties. To do so, we computed Cronbach's alpha values for each MUSIC Inventory scale, we calculated the fit indices and factor loadings using CFA, and we calculated correlation coefficients between the MUSIC Inventory scales and measures of engagement.

The Cronbach's alpha values were all found to be good or excellent, indicating that the translated scales were reliable for the use with the Chinese and Spanish samples. The alpha values for the Chinese sample were slightly lower than those in the Spanish sample, but not by much. The high alpha values that we documented indicate that individuals using the MUSIC Inventory could expect to obtain consistent scores from the inventory scales. 


\section{Jones-Validation of the MUSIC Model}

We conducted CFAs to examine how the items in the MUSIC Inventory fit the five-factor structure of the MUSIC model. Because no one test exists to assess the fit of data to a model, we examined three different fit indices and the item factor loadings to examine the fit of the data to the model. Using the criteria we established a priori (based on Browne \& Cudeck, 1993; Byrne, 2001; Hu \& Bentler, 1999; Kline, 2005), data from both the Chinese and Spanish translations of the MUSIC Inventory were a reasonable fit to the five-factor structure of the MUSIC model. The factor loadings were also much higher than our a priori criterion value of .32 (Tabachnick \& Fidell, 1996), which provided further evidence that the data fit the five-factor structure of the MUSIC model.

We compared the alpha values and fit indices from the Chinese and Spanish translations to the English version presented by Jones and Skaggs (2016). Overall, the alpha values from the Chinese and Spanish samples were similar to the alpha values reported by Jones and Skaggs (2016) in an American sample (see Table 1). The values for the CFI, SRMR, and RMSEA were also similar to those reported for an American sample (Jones \& Skaggs, 2016). The fact that the alpha values and fit indices were similar across undergraduate students from China, Colombia, and the US, is interesting for a couple reasons. First, the similarities across different cultures indicates that the Chinese and Spanish translations were done well and produce scores as valid as those produced by the English version. Because of this, we have documented that these translations demonstrate acceptable psychometric properties. Second, the similarities across different cultures provides evidence that the MUSIC model is generalizable to at least some undergraduate students in Chinese and Hispanic cultures. That is, students in these cultures can perceive the MUSIC model components differently in an instructional setting. This is evidenced by the fact that the MUSIC model components separated into distinct factors in our CFA. We expected this finding because the MUSIC model was developed based on research and theories that apply to humans, regardless of race or nationality. For example, the MUSIC model suggests that instructors should interest students in the class content because all humans have a need for arousal (Berlyne, 1960). 
As further evidence of the validity of the scores produced by the translated MUSIC inventories, we documented that students' perceptions of the five MUSIC model components were moderately correlated with behavioral and cognitive engagement, as we had predicted. These findings are important for theoretical and practical reasons. Theoretically, Jones (2009, 2015) explained that when students have higher perceptions of each of the MUSIC model components, they are more likely to have greater motivation and higher levels of engagement. The findings from the present study provide further evidence for this assertion because all of the MUSIC components were moderately correlated with behavioral and cognitive engagement; thus, this study contributes to our understanding of the theoretical relationships among these constructs. Practically, the relationships between the MUSIC components and engagement are important because they indicate that professors may be able to use teaching strategies intentionally to increase students' perceptions of the MUSIC components, which may then increase their motivation and engagement in their courses. In fact, interventions designed to increase students' perceptions of one or more of the MUSIC model components have led to increases in students' motivation and engagement (for examples, see Brown, Smith, Thoman, Allen, \& Muragishi, 2015; and Lazowski \& Hulleman, 2016).

\section{Limitations and Future Research}

One of the limitations of this study is that the participants are not representative of all undergraduate students who speak Chinese or Spanish. Future research could survey a broader variety of students and majors. In addition, future studies could compare differences between students in countries that speak the same language. One possible question related to this point is: To what extent is the Spanish translation of the MUSIC Inventory valid for use with students in Spain? Although students in both Colombia and Spain speak Spanish, differences in dialect and culture may affect the scores produced on the Spanish translation of the MUSIC Inventory. Similarly, it would be useful to assess students in different regions of a country, such as in different regions of China. 
Jones $(2009,2015)$ contends that the MUSIC model can be used for any type of instruction (e.g., lecture, problem-based learning, discussion). Therefore, in the present study, we did not compare the results across teaching approaches. By including a variety of teaching approaches in the present study, we assumed that the psychometric properties of the MUSIC Inventory were similar across teaching approaches, and therefore, that the findings could be generalized to all teaching approaches. In the future, researchers could examine whether the psychometric properties of the MUSIC Inventory vary across teaching approaches. For example, the inventory may prove to be more reliable for lecture classes than classes that employ problem-based learning approaches.

\section{Implications and Conclusion}

The Chinese and Spanish translations of the College Student version of the MUSIC Inventory demonstrate acceptable psychometric properties for use with undergraduate students. Therefore, instructors and researchers can use the inventories to assess students' perceptions of the five MUSIC model components. As described in greater detail elsewhere (Jones, 2009, 2015), instructors can use the results of the MUSIC Inventory to improve their instruction. For example, if students report low scores on the usefulness scale, instructors can consider strategies to help students understand the usefulness of the class material. Researchers can also use the inventories to assess students' perceptions of instruction, for example, after conducting an intervention. Or, to examine the relations between the MUSIC model components and other antecedents and consequences (e.g., Jones et al., 2015). 


\section{References}

Berlyne, D. E. (1960). Conflict, arousal, and curiosity. New York: McGrawHill. doi:10.1037/11164-000

Brown, E. R., Smith, J. L., Thoman, D. B., Allen, J. M., \& Muragishi, G. (2015). From bench to bedside: A communal utility value intervention to enhance students' biomedical science motivation. Journal of Educational Psychology, 107(4), 1116-1135. doi:10.1037/edu0000033

Browne, M. W., \& Cudeck, R. (1993). Alternative ways of assessing model fit. In K. A. Bollen \& J. S. Long (Eds.), Testing structural equation models (pp. 445-455). Newbury Park, CA: Sage.

Byrne, B. M. (2001). Structural equation modeling with AMOS: Basic concepts, applications, and programming. Mahwah, NJ: Lawrence Erlbaum.

George, D., \& Mallery, P. (2003). SPSS for Windows step by step. New York: Allyn and Bacon.

Hu, L. T., \& Bentler, P. M. (1999). Cutoff criteria for fit indices in covariance structure analysis: Conventional criteria versus new alternatives. Structural Equation Modeling, 6, 1-55. doi:10.1080/10705519909540118

Jones, B. D. (2009). Motivating students to engage in learning: The MUSIC Model of Academic Motivation. International Journal of Teaching and Learning in Higher Education, 21(2), 272-285.

Jones, B. D. (2010). An examination of motivation model components in face-to-face and online instruction. Electronic Journal of Research in Educational Psychology, 8(3), 915-944.

Jones, B. D. (2015). Motivating students by design: Practical strategies for professors. Charleston, SC: CreateSpace.

Jones, B. D. (2012). User guide for assessing the components of the MUSIC Model of Academic Motivation. Retrieved from http://www.theMUSICmodel.com

Jones, B. D., Epler, C. M., Mokri, P., Bryant, L. H., \& Paretti, M. C. (2013). The effects of a collaborative problem-based learning experience on students' motivation in engineering capstone courses. 
Interdisciplinary Journal of Problem-based Learning, 7(2), 34-71. doi:10.7771/1541-5015.1344

Jones, B. D., Osborne, J. W., Paretti, M. C., \& Matusovich, H. M., (2014).

Relationships among students' perceptions of a first-year engineering design course and their engineering identification, motivational beliefs, course effort, and academic outcomes. International Journal of Engineering Education, 30(6A), 1340-1356.

Jones, B. D., \& Sigmon, M. L. (2016). Validation evidence for the elementary school version of the MUSIC ${ }^{\circledR}$ Model of Academic Motivation Inventory. Electronic Journal of Research in Educational Psychology, 14(1), 155-174. doi:10.14204/ejrep.38.15081

Jones, B. D., \& Skaggs, G. E. (2016). Measuring students' motivation: Validity evidence for the MUSIC Model of Academic Motivation Inventory. International Journal for the Scholarship of Teaching and Learning, 10(1), 1-9. doi:10.20429/ijsotl.2016.100107

Jones, B. D., Tendhar, C., \& Paretti, M. C. (2015). The effects of students' course perceptions on their domain identification, motivational beliefs, and goals. Journal of Career Development. Advance online publication. doi:10.1177/0894845315603821

Jones, B. D., Watson, J. M., Rakes, L., \& Akalin, S. (2012). Factors that impact students' motivation in an online course: Using the MUSIC Model of Academic Motivation. Journal of Teaching and Learning with Technology, 1(1), 42-58.

Jones, B. D., \& Wilkins, J. L. M. (2013). Testing the MUSIC Model of Academic Motivation through confirmatory factor analysis.

Educational Psychology: An International Journal of Experimental Educational Psychology, 33(4), 482-503. doi:10.1080/01443410.2013.785044

Jones, B. D., \& Wilkins, J. (2015, February). More validity evidence for the use of the MUSIC Model of Academic Motivation Inventory with upper-elementary and middle school students. Poster presented at the annual meeting of the Eastern Educational Research Association, Sarasota, Florida.

Kline, R. B. (2005). Principles and practice of structural equation modeling. New York, NY: Guilford Press.McGinley, J., \& Jones, B. D. (2014). 
A brief instructional intervention to increase students' motivation on the first day of class. Teaching of Psychology, 41(2), 158-162. doi:10.1177/0098628314530350

Lazowski, R. A., \& Hulleman, C. S. (2016). Motivation interventions in education: A meta-analytic review. Review of Educational Research, 86(2), 602-640. doi:10.3102/0034654315617832

McGinley, J., \& Jones, B. D. (2014). A brief instructional intervention to increase students' motivation on the first day of class. Teaching of Psychology, 41(2), 158-162. doi:10.1177/0098628314530350

Mohamed, H. E., Soliman, M. H., \& Jones, B. D. (2013). A cross-cultural validation of the MUSIC Model of Academic Motivation and its associated inventory among Egyptian university students. Journal of Counseling Quarterly Journal, 36, 2-14.

Parkes, K., Jones, B. D., \& Wilkins, J. (2015). Assessing music students' motivation using the MUSIC Model of Academic Motivation Inventory. UPDATE: Applications of Research in Music Education. Advance online publication. doi:10.1177/8755123315620835

Plant, R. W., \& Ryan, R. M. (1985). Intrinsic motivation and the effects of self-consciousness, self-awareness, and ego-involvement: An investigation of internally-controlling styles. Journal of Personality, 53(3), 435-449. doi:10.1111/j.1467-6494.1985.tb00375.x

Schram, A. B., \& Jones, B. D. (2016). A cross-cultural adaptation and validation of the Icelandic version of the MUSIC Model of Academic Motivation Inventory. Icelandic Journal of Education, 25(2), 159-181.

Shell, D. F., \& Husman, J., (2008). Control, motivation, affect, and strategic self-regulation in the college classroom: A multidimensional phenomenon. Journal of Educational Psychology, 100(2), 443-459. doi: 10.1037/0022-0663.100.2.443

Shell, D. F., Husman, J., Turner, J. E., Cliffel, D. M., Nath, I., \& Sweany, N. (2005). The impact of computer-supported collaborative learning communities on high school students' knowledge building, strategic learning, and perceptions of the classroom. Journal of Educational Computing Research, 33(3), 327-349. doi:10.2190/787L-BCBQ20FN-FW6C 
Tabachnick, B. G., \& Fidell, L. S. (1996). Using multivariate statistics (3rd ed.). New York: HarperCollins.

Tendhar, C. (2015). Effects of motivational beliefs and instructional practice on intention to pursue majors and careers in engineering (Unpublished doctoral dissertation). Virginia Tech, Blacksburg, VA. Villagran, M. M., \& Lucke, J. F. (2005). Translating communication measures for use in non-English-speaking populations.

Communication Research Reports, 22(3), 247-251. doi:10.1080/00036810500230743

Wang, M.-T., Fredricks, J. A., Ye, F., Hofkens, T. L., \& Linn, J. S. (2016). The math and science engagement scales: Scale development, validation, and psychometric properties. Learning and Instruction. doi10.1016/j.learninstruc.2016.01.008

Brett D. Jones is a full Professor and the Educational Psychology Program Leader in the School of Education at Virginia Tech.

Ming Li is a doctoral candidate at Virginia Tech and an Associate Professor in the School of Foreign Languages at Sias International University.

Juan M. Cruz is a graduate student of Engineering Education at Virginia Tech and an Assistant Professor of the School of Engineering at Universidad Javeriana in Colombia.

Contact Address: Brett D. Jones, Virginia Tech, School of Education (0313), Blacksburg, VA, U.S. (brettdjones@gmail.com) 
Instructions for authors, subscriptions and further details:

http://ijep.hipatiapress.com

\section{Japanese and Korean Kindergartners' Perspectives of Play Using Photos}

Satomi Izumi-Taylor, ${ }^{1}$ Yeonsun (Ellie) Ro, ${ }^{2}$ Jihee Han, ${ }^{3}$ Yoko Ito ${ }^{4}$

1) The University of Memphis

2) Institution of Early Global Education

3) Eui-Myung Kindergarten

4) Chiba University

Date of publication: February $24^{\text {th }}, 2017$

Edition period: February 2017 - June 2017

To cite this article: Izumi-Taylor, S., Ro, Y., Han, J., \& Yoko Ito. (2017). Japanese and Korean Kindergartners' Perspectives of Play Using Photos. International Journal of Educational Psychology, 6(1), 45-66. doi: 10.17583/ijep.2017.2049

To link this article: http://dx.doi.org/10.17583/ijep.2017.2049

\section{PLEASE SCROLL DOWN FOR ARTICLE}

The terms and conditions of use are related to the Open Journal System and to Creative Commons Attribution License (CC-BY). 


\section{Japanese and Korean Kindergartners' Perspectives of Play Using Photos}

Satomi Izumi-Taylor

The University of Memphis

Jihee Han

Eui-Myung Kindergarten
Yeonsun (Ellie) Ro

Institution of Early Global Education

Yoko Ito

Chiba University

\section{Abstract}

The purpose of the study was to examine Japanese and Korean kindergarteners' perspectives by asking them to photograph play and explain why their photos represent play (photo elicitation interviews). The participants consisted of 50 kindergarteners on Japan's main island and 50 kindergarteners in South Korea. Japanese and Korean kindergartners were provided with digital cameras and were asked to photograph their views of play without adult accompaniment. Afterwards, the children were asked to describe why their photos represented play. "Can you tell me why this means play to you?" The data were analyzed using content and thematic analyses and the photos were reviewed along with children's responses. The thematic analysis of results revealed that Japanese and Korean kindergartners' perceptions were related to interactions with other children, pretend play, schoolyards, and toys or props. The findings of this study indicated the ways in which Japanese and Korean children's play perceptions were related to cultural and social contexts. Implications for early childhood education were also discussed.

Keywords: Japanese and Korean children's views of play, photo elicitation interviews with Japanese and Korean children, comparative study 


\section{Perspectivas sobre el Juego en Infantil de Niños y Niñas Japoneses y Coreanos}

Satomi Izumi-Taylor

The University of Memphis

Jihee Han

Eui-Myung Kindergarten

\author{
Yeonsun (Ellie) Ro \\ Institution of Early Global Education \\ Yoko Ito \\ Chiba University
}

\section{Resumen}

El objetivo del estudio fue examinar las perspectivas de los niños japoneses y coreanos de educación infantil pidiéndoles que fotografiaran y explicaran por qué sus fotos representan el juego (entrevistas de elicitación fotográfica). Los participantes consistieron en 50 niños de la isla principal de Japón y 50 de Corea del Sur. Los niños de educación infantil japoneses y coreanos recibieron cámaras digitales y se les pidió que fotografiaran sus puntos de vista del juego sin acompañamiento de adultos. Posteriormente, se pidió a los niños que describieran por qué representaban sus fotos. "¿Puedes decirme por qué esto significa para ti jugar?" Los datos fueron analizados mediante análisis de contenido y temáticos y las fotos fueron revisadas junto con las respuestas de los niños. El análisis temático de los resultados reveló que las percepciones de los niños japoneses y coreanos estaban relacionadas con las interacciones con otros niños, juegos de simulación, patios escolares y juguetes o accesorios. Los hallazgos de este estudio indicaron las maneras en que las percepciones de juego de niños japoneses y coreanos estaban relacionadas con contextos culturales y sociales. También se discutieron las implicaciones para la educación de la primera infancia.

Palabras clave: Perspectivas sobre el juego en niños japoneses y coreanos, entrevistas estimuladas con fotgrafías, estudio comparativo 
onsider the following humorous phrases by Japanese and Korean kindergartners when asked to take pictures and describe why they considered it to be play: "I photographed this chicken's egg because when we take care of the chickens, we can keep their eggs," "I love this space between these two buildings," "Boys are making something with blocks," and "Because someone folds paper to make something that flies."

Although adults are familiar with their own play perspectives, we know little of children's (Izumi-Taylor, Ito, \& Krisell, 2016). What constitutes play for adults might not be the same for children. Play is defined as behavior that leads to all phases of development within the cultural context in which players interact (Kieff \& Casbergue, 2000). Many educators agree that "Play is an important vehicle for developing self-regulation as well as for promoting language, cognition, and social competence" (Copple \& Bredekamp, 2009, p. 14). Yet, we debate about what are the best practices in early childhood education when teachers are required to implement academic curricula (National Council of Accreditation for Teacher Education, 2014; Russell, 2011). Teachers have some trepidation about focusing on only standardized test scores (Follari, 2011) and lack the time and training to provide developmentally appropriate play activities (DeVries, Zan, Hildebrant, Edmiaston, \& Sales, 2002). When teachers adhere only to slogans that play is the best way for children to learn, a shallow understanding may lead to implementing play-oriented curricula that may be "nothing more than entertainment" (DeVries et al., 2002, p. 6). Teachers can offer appropriate play activities when given clear and detailed descriptions of such.

Because much of American research on early childcare in the past two decades has been conducted on "middle class, European American families" (Johnson, Jaeger, Randolph, Cause, Ward \& National Institute of Child Health and Human Development Early Child Care Research Network, 2003, p. 1227), studying children's play perspectives in two Asian countries might provide more universal views. As children's notions of play are culturally related (Izumi-Taylor, Ito, \& Krisell, 2016), their values and attitudes might also influence their perceptions. In spite of cultural, educational, and political differences, early childhood educators in Japan and Korea recognize 
play as fundamental (Izumi-Taylor \& Ro, 2016); however, Japanese children's views of play might differ from those of Korean children.

As there is a growing global focus on child-centered education and care (Roopnarine, 2015), examining children's views of play in Japan and Korea might provide a universal understanding of "global issues of meeting the culturally, developmentally appropriate needs of young children" (Roopnarine, 2015, p. 1). Through such examination, we can better prepare teachers to work with children and families from diverse cultural backgrounds. Identifying and examining similarities and differences in children's views of play in different cultures assists scholars and educators in improving their own childcare practices.

\section{The Purpose of the Study}

The purpose of the study was to examine Japanese and Korean kindergarteners' perspectives by asking them to photograph play and explain why their photos represent play (photo elicitation interviews). Because young children have difficulty verbally expressing themselves (Einarsdotti, 2005; Pink, 2013; Thompson \& Williams, 2009), through photo elicitation interviews (PEIs) (Phelan \& Kinsella, 2011; Pink, 2013; Thompson \& Williams, 2009), they can reveal their perspectives. Photography can support children's explanations of school activities (Ching, Wang, Shih, \& Kedem, 2006; Clark-Ibanez, 2004; DeMarie, 2001; DeMarie \& Ethridge, 2006; Kirova \& Emme, 2009).

Finding out a children's views of play as they actively participate in it would provide important sources for educators and others involved in children's lives (Ramazan, Ozdemir, \& Beceren, 2012). There exists limited and outdated research on children's perceptions of play in different cultures (Izumi-Taylor, Ito, \& Krisell, 2016). For these reasons, this study was conducted to address such limitations, guided by these research questions: 1 . What views are revealed in Japanese and Korean kindergartners' photos of play? And 2. Are there any similarities or differences among their views? If so, how are they similar or different? This paper first outlines the contexts concerning previous studies of children's views of play and PEIs, early childhood education and play in Japan and Korea, and is followed by a 
report on the study, analysis of findings, and discussions of implications and limitations for early childhood education.

\section{Previous Studies of Children's Views of Play and PEIs}

Generally, children's favorite activity at school was play, and they enjoyed selecting their own play activities (Wiltz \& Klein, 2001). Children's perceptions of play were related to games, mini-gyms, and playing with other children (Fivush, 1984). Young children viewed school as work, and recess as play (Dockett, 2002). Kindergartners and first/second graders preferred play over work (Wing, 1995), and child-initiated play was considered play, while teacher-initiated activities were viewed as work (Cooney, Gupton, \& O’Laughlin, 2000; Cunningham \& Weigel, 1992). Dockett and Meckley (2007) found that American and Australian children said playing with friends was important, and they enjoyed recreational play but disliked teachers' involvement. Children's views and experiences at a schoolyard in Greece were examined through interviews and drawings, and it was found that children enjoyed "strolling around and talking with friends as their favorite activity in the school ground" (Christidou, Tsevreni, Epitropou, \& Kittas, 2013, p. 71).

These studies mentioned above examined children's perspectives of play through interviews, but young children often found it difficult to verbally express their views, and their responses could have been limited (IzumiTaylor, Ito, \& Krisell, 2016). To address such limitations, asking them to photograph their views of play might provide opportunities to express their meanings freely (Izumi-Taylor et al., 2016; Phelan \& Kinsella, 2011). Through this method, children were empowered (Izumi-Taylor et al., 2016), and photographing their play could help us understand children's definitions of it. As many teachers report having difficulties in offering children creative play activities (Levin, 2013), awareness of children's play perspectives could assist in offering quality play experiences.

Photography can represent children's meanings of their activities (DeMarie, 2001; DeMarie \& Ethridge, 2006; Einarsdottir, 2005; Kumpulainen, Lipponen, Hilppo, \& Mikkola, 2013; Sairanen \& Kumpulainen, 2014). When asked to photograph people or things with 


\section{Izumi-Taylor et al.-Kindergartners' Perspectives of Play}

"social attachments and meaning" to explain their lives, children photographed their play interactions with others (Clark-Ibanez, 2004). Asking them to take photos to express the meaning of their lives can provide us with authentic understanding of their perceptions (Byrnes \& Wasik, 2009; DeMarie \& Ethridge, 2006; Kumpulainen et al., 2013). A study examining Italian children's perceptions of a park through photography (Gandini, 2012) found that children were capable of showing their ideal "green areas in their courtyards," and they preferred playing with friends (p. 3). "Children were quite interested in the depth and distance of the landscape and the absence of obstacles like walls and bushes" (Gandini, 2012, p. 7). Children's perspectives of school lives in Iceland through photography revealed they enjoyed taking pictures and using them to communicate their thinking with others (Einarsdottir, 2005). In this study children's photographs were influenced by accompanying adults, and when they freely took pictures with no adults present, they took unique pictures, including "bathrooms, hallways, and cubbies" where they could wander and explore.

When Izumi-Taylor and her colleges (2016) asked both American and Japanese kindergartners to take pictures and explain their views of play, a majority photographed outdoor play with other children. It was found that both American and Japanese children's play perspectives were related to interactions with others, preferred environments, and favorite toys/props. Only Japanese children took photos of toys/props without people, but this was not the case for American children. When asked to explain their pictures, many American and Japanese children described the content. There are no studies of children's views of play in Japan, but one study utilizing children's photos revealed photography was an effective tool to understand how children can express their meaning of life when photographing favorite items, current interests, and memorable events (Oishi, 2010). Another Japanese study (Teramoto \& Ohnishi, 1995) examined elementary and junior high school students' concepts of schools, asking them to photograph their environments using PEIs. Students photographed schoolyards where they enjoyed playing and communicating with others. There exists no study of Korean children's perceptions of play. 


\section{Japanese and Korean early Childhood Education and Play}

In Japan, the National Curriculum Standards for Kindergarten (the Course of Study for Kindergarten) set forth by the government describe how play promotes children's learning and developing balanced minds and bodies (The Ministry of Education, Culture, Sports, Science, and Technology, 2008). Japanese early childhood education curricula are based on specific guidelines that mandate play-centered education in group-oriented environments (Izumi-Taylor \& Ro, 2016). Children-initiated play is highly valued, and adults need not force participation in play activities. Teachers generally support children's play based on the cultural belief that play should be valued for itself rather than how it promotes children's education (Izumi-Taylor \& Ro, 2016). Teachers must support and facilitate such activities for children. To encourage engagement in play, teachers should focus on cultivating children's spirit of inquiry, interests, abilities to relate positively with their environments, capacities to innovate, and abilities to solve problems.

In Korea, the National Common Curriculum Standards set forth by the government emphasize "child-centered and play-based curricula" as play is one of the best ways to enhance children's creativity, development and learning (KICCE, 2013, p. 3). Kindergartens follow a national curriculum entitled the Nuri curriculum (Park, Jang, \& Park, 2016) which describes five primary domains of early childhood education: physical activity and health; communication; social interactions; art experiences; and nature exploration (Ministry of Education, 2015). The philosophy of the Nuri curriculum delineates that any activity in preschools and kindergartens should promote these five areas, and play-oriented educational activities are encouraged. Korean kindergarten teachers need to integrate play into curricula rather than just providing activities, and allowing children ample time to explore and experience the world in carefully designed educational and playful settings is important (KICCE). Early childhood educators are expected to offer various kinds of pretend play settings, including banks, restaurants, and libraries in order for children to experience preparation for real-life (Izumi-Taylor \& Ro, 2016). 


\section{Izumi-Taylor et al.-Kindergartners' Perspectives of Play}

One study conducted in Korea revealed that the word, play, was used in conjunction with activities in order to diminish the negative image of play being interpreted as only playing (Park \& Park, 2014). In the Nuri curriculum guideline, many different kinds of play are introduced, including traditional Korean cultural play, group and individual play, pretend play, and play in nature (Ministry of Education, 2015). The Nuri curriculum handbook presents a new direction toward multicultural education for young learners to become global citizens (Hoot, Bakuza, Lavasani, Park, Sharifian, \& Szecsi, 2015).

\section{Method}

\section{Participants}

The participants consisted of 50 kindergarteners (five year olds) on Japan's main island, and 50 kindergarteners (five year olds) in South Korea. The respondent pool was selected through convenience of access and availability (Hancock \& Algozzine, 2006). Our respondent pool was children who "may have the best information with which to address the study's research questions" (Hancock \& Algozzine, 2006, p. 40). School directors informed parents that children's participation was voluntary, and not participating would not negatively affect them. Children aged three to five attended Japanese preschools called kindergartens (Izumi-Taylor, 2013). The Japanese school in the study served children from middle-class families and were close to playgrounds, and all children were Japanese. This school valued play, and the children engaged in group-oriented activities. The Korean kindergarten served children from middle-class families. The playground is attached to the building, and all children were Korean. Play was valued at this school, and the children often engaged in both individualand group-oriented activities.

\section{Data Collection}

The fourth author collected the Japanese data, and the third author collected the Korean data. Both authors provided Japanese and Korean 
kindergarteners with digital cameras and asked them to photograph their views of play without adult accompaniment. We requested two photos from each child, some taking only one, others taking two. Japanese children took more photos than their Korean counterparts. Afterwards, these authors showed their photos to children and asked to describe why the photos represented play, by asking "Can you tell me why did this means play to you?"

\section{Data Analysis}

The first author translated Japanese children's responses into English; two Japanese bilingual educators reviewed the responses and agreed on translation (Izumi-Taylor, Ito, \& Gibbons, 2010). The second author followed the same procedures. We analyzed the data using content and thematic analyses and reviewed the photos combined with children's responses as Ray and Smith recommended (2011). "We counted the number of people, items, toys/props, and buildings in each photo" (Izumi-Taylor, Ito, \& Krisell, 2016, p.4). Children's responses were categorized by following Fivush's (1984) coding ("descriptions of the physical environments," "descriptions of an affective state" (p. 1700), descriptions of pretend play and of toys and props, and descriptions of others' talents/skills).

Authors defined the descriptions of photos using children's explanations, such as, "This is my teacher" or "Children are running." Descriptions of the physical environments included, "Children are playing in the hospital, and it looks messy" or "When the sun shines on our forest, we see birds." Affective state referred to such statements as "They are playing together. They are my friends, "or "Children are moving pleasantly." Descriptions of pretend play included: "Four year olds are working at the ice cream store," and "Children are pretending to be anchors on TV." Descriptions of toys or props included, "We play with this toy all the time," or "I love the jungle gym the best." Descriptions of others' talents/skills included: "This child makes cool toys with pine cones," or "This girl can do many tricks on the monkey bars."

"According to its relevance to the study, multiple category codings were counted as separate responses" (Izumi-Taylor, Ito, \& Gibbons, 2010, p. 412) 


\section{Izumi-Taylor et al.-Kindergartners' Perspectives of Play}

because some children gave the same explanations for their photos. Irrelevant responses, such as "This is my photo" was discarded, and some responses were coded more than once.

\section{Results}

Table 1 indicated we counted the contents of each photo, including people, items, toys/props, life forms (chickens and an ant), buildings, and pictures taken outdoors and indoors. Japanese children took photos outdoors (44\%), while Korean children took $28 \%$ of outdoor photos. Korean children took $96 \%$ of photos with people, compared to $30 \%$ by the Japanese. Korean children took $70 \%$ of indoor photos, compared to $22 \%$ by the Japanese. Only Japanese children (26\%) photographed school buildings and chicken coops. Both Japanese and Korean children captured $28 \%$ of pictures of their schoolyards.

Table 1

Content of photos

\begin{tabular}{lcc}
\hline & Japanese children & Korean children \\
\hline people & $30 \%$ & $96 \%$ \\
Outdoors & $44 \%$ & $28 \%$ \\
indoors & $22 \%$ & $70 \%$ \\
school & $26 \%$ & $0 \%$ \\
buildings/chicken & & \\
coops & & \\
Schoolyard & $28 \%$ & $28 \%$ \\
toys/props & $88 \%$ & $52 \%$ \\
life forms only & $8 \%$ & $2 \%$ \\
\hline
\end{tabular}

Qualitative analysis of the data regarding the reasons behind their pictures indicated four themes of children's views of play: interactions with others, pretend play, schoolyards, and toys/props. Each theme was defined as follows: interactions with others refer to children engaging in some activity with others, pretend play is defined as children acting out life situations, schoolyards represent places where children engage in outdoor activities, 
and toys/props include materials, items, and equipment. Table 2 delineated how each response was categorized using some items from Fivush's coding (1984), and we discussed our themes accordingly.

Table 2

Children's reasons for taking photos

\begin{tabular}{|c|c|c|}
\hline & Japanese children & Korean children \\
\hline 1. Descriptions of the photos & $88 \%$ & $100 \%$ \\
\hline $\begin{array}{l}\text { 2. Descriptions of physical } \\
\text { environments }\end{array}$ & $34 \%$ & $10 \%$ \\
\hline $\begin{array}{l}\text { 3. Descriptions of an affective } \\
\text { state }\end{array}$ & $34 \%$ & $8 \%$ \\
\hline 4. Descriptions of toys/props & $84 \%$ & $56 \%$ \\
\hline $\begin{array}{l}\text { 5. Descriptions of others' } \\
\text { talents/skills }\end{array}$ & $12 \%$ & $0 \%$ \\
\hline 6. Descriptions of pretend play & $14 \%$ & $22 \%$ \\
\hline
\end{tabular}

\section{Interactions with Others}

Thirty percent of Japanese and 96\% of Korean children captured photos of children interacting with others, and eight $\%$ of Japanese children's photos contained their teachers while six $\%$ of Korean children included their teachers in their photos. One Korean girl explained her photo, "Children are laughing and singing in a duet." Another girl said, "They are drawing and making something." Two Japanese boys described their pictures thusly, "I photographed everyone playing soccer together," and "I took this because they seemed to be happy." Only Japanese children used the word, friends, to explain their photos suggesting an affective state: "My teacher and my friend are talking to each other," explained one girl. A boy said, "My friends are playing together. They are good to each other."

Regarding these children's photos, many of their reasons were related to descriptions of what children were doing. One Japanese boy who captured two boys on the grass smiling at each other said, I photographed them because they appeared to be enjoying each other's company." One Korean 


\section{Izumi-Taylor et al--Kindergartners' Perspectives of Play}

girl described her photo of children engaging in movement activities, "Children are moving pleasantly." These comments appeared to be associated with both descriptions of photos and an affective state.

Interestingly, only Japanese children's explanations indicated that they seemed familiar with their peers' talents/skills. One boy described his photo of a child working at a table, "This child is very good with his hands and makes pretty pine cone decorations." One girl praised others on a structure by saying, "This is where you can do rope tricks. They are good at this."

\section{Pretend Play}

Korean children $(22 \%)$ photographed more pretend play than their Japanese counterparts (14\%). Two Korean girls' explanations included, "It looks like they are playing on the airplane," and "They are wearing chefs' clothes, getting ready to cook." Two Japanese girls told us: "Four year olds are pretending to run an ice cream store," and "These girls are playing mothers." These children's explanations were related to the descriptions of their photos.

Out of $14 \%$ of such Japanese photos, the majority of children engaged in pretend play in the schoolyard, and $22 \%$ of Korean children's photos were taken indoors. It appeared to show Japanese children's preference for schoolyard play and Korean children's preference for indoor play.

\section{Schoolyards}

Fourteen percent of both Japanese and Korean children's photos were of the schoolyards. Some Japanese photos contained only the schoolyard sans people, while their Korean counterparts took only $2 \%$ of such photos. Again, a strong preference for schoolyard play by Japanese children was evident. Thirty-four percent of Japanese and $10 \%$ of Korean children's descriptions of photos were related to physical environments. One Japanese girl photographed a building in her schoolyard and she explained, "We play many different things in this building," and one boy described his photo of the schoolyard, "We are digging a hole so we can build our new fort here." One Korean girl's photo captured many children playing with boats at a 
small pond in the schoolyard and she claimed, "Children are playing with boats. They are watching boats floating." Another girl's photo captured children on a structure and explained, "They are climbing."

Some Japanese children's explanations of photos were related to an affective state and were associated with nature in the schoolyard. One girl photographed one of the flower gardens in the schoolyard and she opined, "I love this place. Don't you think leaves are pretty?" Another girl captured the schoolyard connected to a small forest, saying "Isn't this place beautiful? The sun is reflecting on trees." One Japanese boy who appeared to be enamored with trains photographed trains traveling a long distance from the schoolyard said, "When I come here, I can see trains going by way over there. I love to watch trains from here." No Korean children took such photos.

\section{Toys/Props}

Eighty-four percent of Japanese and $56 \%$ of Korean children's photos contained toys/props. One Japanese girl photographed only the jungle gym with no one on it saying, "I love this jungle gym best!" Her statement indicated both the descriptions of photos and an affective state. A Japanese boy took a photo of one ball of dirt in a bucket with a spoon with no people around and proudly said, "I created this dirt ball." His explanation was related to descriptions of the photos. One Korean boy captured others in the block center and explained, "Boys are making something with blocks." Another boy's picture contained children playing with toys on the floor and said, "Toys are here and there." These Korean boys described the contents of their photos. Interestingly, many Japanese children photographed toys/props without people while the majority of Korean children's pictures included someone.

As shown in Table 1, 8\% of Japanese and 2\% of Korean children captured life forms including chickens and an ant. The chickens were in coops at the schoolyard, and some of children's explanations included: "This is an overweight chicken," or "I like chickens. When we take care of them, we can keep their eggs." One Korean girl pointing to an ant on the 
schoolyard said, "An ant is moving." All these photos contained just chickens and an ant without people.

\section{Discussion}

The thematic analysis of results reveals how Japanese and Korean kindergartners view play. Their perceptions are related to interactions with other children, pretend play, schoolyards, and toys or props. The following discussion addresses the previous two research questions simultaneously.

\section{Japanese and Korean Kindergartners' Views of Play}

Similarities and Differences: Both Japanese and Korean children freely photographed their views of play and provided reasons for the photos. Korean children took more photos indoors than outdoors, compared to their Japanese counterparts. The fact that Japanese children photographed more outdoor play than their Korean counterparts might be related to the school environments that provide nature and living life forms such as chickens to nurture children's love and respect for natural environments (The Ministry of Education, Culture, Sports, Science, and Technology, 2008). Japanese early childhood teachers are expected to support children's minds and bodies in nature. The reasons that Korean children's photos were focused on indoor play might be partially explained by the school's indoor environments that provided many pretend play props, including a stage, airplane, kitchen, fire station, gas station, hospital, and a TV station, etc. (Ministry of Education, 2015). More Korean children's photos captured people than those of the Japanese.

Both Japanese and Korean children's pictures captured their interactions with others, and their reasons for taking such photos coincided with their descriptions of them. These observations were congruent with Fivush's study (1984) that children think it is play if they play with others. DeMarie's study revealed that American preschoolers' photos showed interaction with others when photographing zoo animals (2001). Children are more likely to consider it as play when interacting with others (Christidou et al., 2013; 
Dockett \& Meckley, 2007; Izumi-Taylor et al., 2016; Ramazan et al., 2012). Likewise, Japanese children photographed their preferred play environments where interacting with their peers (Teramoto \& Ohnishi, 1995). When asked to photograph their lives, American children took photos of play with others (Clark-Ibanez, 2004).

Although both Japanese and Korean children photographed pretend play, Japanese children preferred to capture their pretend play in natural outdoor settings, while Korean children's photos were taken in indoor play settings pre-designed by teachers. Again, Japanese children's preference for outdoor play environments was evident. This Japanese preference was further supported by a study (Izumi-Taylor, Ito, \& Krisell, 2016) that Japanese children took more outdoor play photos than their American counterparts.

In line with Korean children's preference for indoor play, their photos of indoor activities might be related to the notion that based on Korean cultural and educational expectations, teachers are trained to be skillful in setting up indoor props that are diverse, and pretend play is one of the highly recommended play methods for teaching young children (Ministry of Education, 2015).

Although both Japanese and Korean children took the same number of photos of schoolyards, more Japanese children captured such photos without people but included flowers, trees, chicken coops, and frosty playgrounds. Some Japanese and Korean children photographed life forms such as chickens and an ant without people. According to DeMarie, children have a tendency to photograph familiar and important things in preschool environments (2001). When asked to photograph their views of school, many young children photographed playgrounds, and some took pictures of familiar living forms (Christidou et al., 2013; Einarsdotti, 2005; DeMarie, 2001; Izumi-Taylor et al., 2016; Kumpulainen et al., 2013).

These Japanese children appeared to be sensitized to their natural surroundings, and some reasons for taking such photos were related to their feelings. Similarly, a study of American and Japanese children's perceptions of play (Izumi-Taylor, Ito, \& Krisell, 2016) revealed that more Japanese children related their views of play to natural outdoor settings than their American counterparts. These Japanese children's views of play might be partially influenced by their culture as the Japanese teachers in this study 


\section{Izumi-Taylor et al.-Kindergartners' Perspectives of Play}

provided natural environments where children can appreciate flowers, trees, chickens, and frosty playgrounds. Japanese children must experience nature to develop rich emotions and to understand how to care for living things through play (The Ministry of Education, Culture, Sports, Science, and Technology, 2008). Additionally, some Japanese children's photos captured the depth and distance of the schoolyard and appeared to show their interests in walls, bushes, trains, chicken coops, bathrooms, forts, and play structures sans people. These observations were further corroborated by others (Einarsdotti, 2005; Gandini, 2012) claiming that given opportunities, children tended to be interested in various areas in schoolyards where they can explore and wander, and they were able to see objects/items beyond the schoolyard.

While both Japanese and Korean children included toys/props in their photos, Japanese children's explanations were more associated with emotions and interests than their Korean counterparts. Japanese educational guidelines (Ministry of Education, Culture, Sports, Science, and Technology, 2008) clearly state that teachers must support children's abilities to care for their environments, including taking care of their play materials. Contrarily, Korean children's explanations of such were related to how children were engaging in pretend play settings with others. Again, Korean children's preference for interacting with others during play was evident. It appeared that because Korean teachers are required to provide children opportunities to engage with various kinds of pretend play materials in group settings, these children's explanations were influenced by their environments (Izumi-Taylor \& Ro, 2016; Ministry of Education, 2015). Through such environments, teachers aim to develop children's social skills and to enact real-life situations.

\section{Implications and Limitations}

Although it might be difficult to draw a conclusion from children's photos of play to understand teachers' attitudes about play, each of the themes that emerged from the data could provide an insight and reflection for teachers. The findings of this study indicate the ways in which Japanese and Korean 
children's play perceptions are related to their cultural and social contexts. With new teaching methods significantly impacting on the potential of teachers to connect around the globe, educators in different cultural contexts might work together to expand their understanding of children's views of play. As part of this collaboration, teachers could also observe the effective methods to create educational materials and effective play environments. By doing so, teachers from different nations can understand how they can better assess the play-related activities in their own classrooms by including everyone involved in children's education. Teachers might provide space to understand and to appreciate the different views of play held by young children, through open debate about play in both general and applied contexts.

In the process of collaboration, teachers can examine how children see play and what is the best way to provide appropriate play activities. By understanding and appreciating each country's children's similar and different views of play, teachers can integrate appropriate play activities in the classroom.

When everyone involved in young children's care and education respects and values different perspectives of play held by children in our world, it helps educators to understand how to create play environments that are based on children's interests and needs because play appears to serve as a vehicle to unify and integrate all dimensions of learning and development. Educators need to fully realize and listen to children's voices. One way to do this is through PEIs. Through PEIs, adults can listen and understand children's opinions and views of school activities.

The results of this study must be considered limited given the size and particularity of the two samples from middle-class-families, and children from different class families should be included to better understand their views of play. Additionally, some Japanese children took more photos than their Korean counterparts that could have influenced our interpretations of children's views of play. 
62 Izumi-Taylor et al.-Kindergartners' Perspectives of Play

\section{References}

Byrnes, J., \& Wasik, B. (2009). Picture this: using photography as a learning tool in early childhood classrooms. Childhood Education, 85(4), 243248. doi:10.1080/00094056.2009.10523090

Ching, C., Wang, X., Shih, M., \& Kedem, Y. (2006). Digital photography and journals in a kindergarten-first-grade classroom: Toward meaningful technology integration in early childhood education, Early Education and Development, 17(3), 347-371.

doi:10.1207/s15566935eed1703 3

Christidou, V., Tseverni, I., Epitropou, M., \& Kittas, C. (2013). Exploring primary children's views and experiences of the school ground: The care of a Greek school. International Journal of Environmental \& Science Education, 8(1), 59-83.

Clark-Ibanez, M. (2004). Framing the social world with photo-elicitation interviews. American Behavior Scientists, 47(12), 1507-1526. doi: $10.1177 / 0002764204266236$

Cooney, M., Gupton, P., \& O'Laughlin, M. (2000). Blurring the lines of play and work to create blended classroom learning experiences. Early Childhood Education Journal, 27(3), 165-171. doi:10.1007/BF02694230

Copple, C., \& Bredekamp, S. (2009). Developmentally appropriate practice in early childhood programs serving children from birth through age 8 (3rd Ed.). Washington, DC: NAEYC.

Cunningham, B., \& Weigel, J. (1992). Preschool work and play activities: Child and teacher perspectives. Play and Culture, 5, 92-99.

DeMarie, D. (2001). A trip to the zoo: Children's words and photographs. Retried from: http://ercp.uiuc.edu/v3n1/demarie.html

DeMarie, D., \& Ethridge, E. (2006). Children's images of preschool: The power of photography. Young Children, 61(1), 101-104.

DeVries, R., Zan, R., Hildebrandt, C., Edmiaston, R., \& Sales, C. (2002). Developing constructivist early childhood curriculum. New York: Teachers College Press.

Dockett, S. (2002). Teachers don't play! Children's views of play at school. Play and Folklore, 42, 9-12. 
Dockett, S., \& MecKely, A. (2007). What young children say about play at school: Unites States and Australian comparisons. In D. Sluss, \& O. Jarrett. (Eds.), Play and Culture Studies (pp. 88-113). Lanham, MD: University Press of America.

Einarsdottir, J. (2005). Playschool in pictures: children's photographs as a research method. Early Child Development and Care, 175(6), 523541. doi:10.1080/03004430500131320

Fivush, R. (1984). Learning about school: The development of kindergartners' school scripts. Child Development, 55(5), 1697-1709.

Follari, L. (2011). Foundations and best practices in early childhood education: History, theories, and approaches to learning. Upper Saddle River, NJ: Pearson Education Inc.

Gandini, L. (2012). Imagining, designing, constructing and living in the park of the Martiri di Sesso preschool. Innovations in Early Education, the International Reggio Exchange, 19(3), 1-14.

Hancock, D., \& Algozzine, B. (2006). Doing case study research. New York, NY: Teachers College Press.

Hoot, J. L., Bakuza, F. R., Lavasani, M. G., Park, S. R., Sharifian, M. S., \& Szecsi, T. (2015). International Perspectives on Early Childhood Teacher Education. In L. Couse, \& S. Recchia (Eds.), Handbook of Early Childhood Teacher Education (pp. 348-363). Abingdon, UK: Routledge.

Izumi-Taylor, S. (2013). Scaffolding in group-oriented Japanese preschools. Young Children, 68(1), 70-75.

Izumi-Taylor, S., Ito, Y., \& Gibbons, A. (2010). Early childhood pre-service teachers' perceptions of teaching technology to children in Japan and the United States. Research in Comparative and International Education, 5(4), 408-420. doi:10.2304/rcie.2010.5.4.408

Izumi-Taylor, Ito, Y., Krisell, M. (2016). American and Japanese kindergarteners' views of play through the use of photo elicitation interviews (PEIs). Research in Comparative and International Education. doi:10.1177/17454999/6663379

Izumi-Taylor, S., \& Ro, Y. (2016). Japanese and Koran children's ideas of play through photo elicitation interviews (PEIs). Poster presented at the National Association for the Education of Young Children. Anaheim, CA. 
Johnson, D., Jaeger, S., Randolph, M., Cauce, A., Ward, and National Institute of Child Health and Human Development Early Child Care Research Network. (2003). Studying the effects of early child care experiences on the development of children of color in the United States: Toward a more inclusive research agenda. Child Development,74(5), 1227-1244.

Keiff, J., \& Casbergue, R. (2000). Playful learning and teaching: Integrating play into pre school and primary program. Needham Heights, MA: Allyn \& Bacon.

KICCE: Korean Institute of Child Care and Education (2013). Policy brief: Nuri curriculum ( $\left.2^{\text {nd }} E d s.\right)$. Seoul, Korea: KICCE.

Kirova, A., \& Emme, M. (2009). Immigrant children's bodily engagement in accessing their lived experiences of immigration: Creating poly-media descriptive texts. Phenomenology \& Practice, 3(1), 59-79.

Kumpulainen, K., Lipponen, L., Hilppo, J., \& Mikkola, A. (2013). Building on the positive in children's lives: a co-participatory study on the construction of children's sense of agency. Early Child Development and Care, 184(2), 211-229. doi:10.1080/03004430.2013.778253

Levin, D. (2013). Beyond remote-controlled childhood: Teaching young children in the media age. Washington, DC: NAEYC.

Ministry of Education, Culture, Sports, Science, and Technology. (2008). Course of study for kindergarten. Retrieved from: http://www.mext.go.jp/english/elsec/1303755.html

Ministry of Education Republic of Korea. (2015). Teachers' guidebook for Nuri curriculum. Retrieved From http://www.moe.go.kr/web/100062/ko/board/view.do?bbsId=315\&bo $\operatorname{ardSeq}=58557$

National Council of Accreditation for Teacher Education. (2014). What makes a teacher effective? Retrieved from: http://www.ncate.org/Public/Research/Reports/TeacherPreparation\%2 0Research/WhatMakesateacherEffective/tabid/361/Default.aspx

Oishi, C. (2010). Photo projective method as a tool for expressing one's identity. Bulletin of Tokyo Women's College of Physical Education, 45, 131-141.

Park, E., Jang, M., \& Park, S. (2016). Early childhood education policies in Korea: Advances in theory and practice. In H. Lin, E. Park, and J. 
Chen (Eds.). Early childhood policies in Asia and Pacific (pp. 87107). Singapore: Springer.

Park, S., \& Park, E. (2014). Text network analysis of national kindergarten curriculum focusing on play: From the $1^{\text {st }}$ national kindergarten curriculum to Nuri curriculum. International Journal of Child Care and Education Policy, 8(1), 12-21.

Phelan, S., \& Kinsella, E. (2011). Photo elicitation interview methods and research with children. Qualitative Researching: Living Research, 5, 125-134. 10.3928/00220124-20110823-04

Pink, S. (2013). Doing visual ethnography (3rd ed). London, UK: Sage.

Ramazan, A., Ozdemir, A., \& Beceren, B. (2012). Evaluation of play from private and public pre-school children's point of view. Social and Behavioral Sciences, 46, 2852-2856.

doi:10.1016/j.sbspro.2012.05.576

Ray, J., \& Smith, A. (2011). Using photographs to research organizations:

Evidence, considerations, and application in a field study.

Organizational Research Methods, 15(2), 288-315.

doi:10.1177/1094428111431110

Roopnarine, J. (2015). Play as culturally situated: Diverse perspectives on its meaning and significance. In J. Roopnarine, M. Parre, J. Johnson, \& D. Kuschner (Eds.), International perspectives on children's play (pp. 1-7). New York: McGraw Hill Education.

Russell, J. (2011). From child's garden's academic press: The role of shifting institutional logics in redefining kindergarten education. American Educational Research Journal, 34(3), 195-201. doi:10.3102/0002831210372135

Sairanen, H., \& Kumpulainen, K. (2014). A visual narrative inquiry into children's sense of agency in preschool and 1st grade. International Journal of Educational Psychology, 3(2), 141-174. doi:10.4471/ijep.2014.09

Teramoto, K., \& Ohnishi, K. (1995). Kodomo wa mijikana sekai o do kanjiteiruka [How do children feel about their close environment?]. Aichi Kyouiku Daigaku Kenkyuu Houkoku, 44, 101-117.

Thompson, S., \& Williams, K. (2009). Telling stories with photo essays. Thousand Oaks, CA: Corwin. 
66 Izumi-Taylor et al.-Kindergartners' Perspectives of Play

Wiltz, N., \& Klein, E. (2001). What do you do in child care? Children's perceptions of high and low quality classrooms. Early Childhood Research Quarterly, 16, 209-236.

Wing, L. (1995). Play is not the work of the child: Young children's perspectives of work and play. Early Childhood Research Quarterly, $10,223-247$.

Satomi Izumi-Taylor is a professor of early childhood education and the Youth Services program coordinator with the Department of Instruction and Curriculum Leadership at the University of Memphis in the United States.

Yeon Sun (Ellie) Ro is the director of Institute of Early Global Education in the United States and the invited visiting professor at Sung Kyun Kwan university in Seoul, Korea.

Jihee Han is a principal of Eui-Myung kindergarten and adjunct professor of Chung-Ang university in Seoul, Korea.

Yoko Ito is a professor of the education faculty at Chiba university in Chiba, Japan. Her research interests include cross-cultural studies, home economics, and teacher education.

Contact Address: 400C Ball Hall University of MemphisMemphis, TN 38152 sitaylor@memphis.edu 
Instructions for authors, subscriptions and further details:

http://ijep.hipatiapress.com

\section{Achievement Emotions and Achievement Goals in Support of the Convergent, Divergent and Criterion Validity of the Spanish- Cognitive Test Anxiety Scale}

Javier Sánchez-Rosas, Luis Alberto Furlan

1) National University of Cordoba

Date of publication: February $24^{\text {th }}, 2017$

Edition period: February 2017 - June 2017

To cite this article: Sánchez-Rosas, J. Furlan, LA. (2017). Achievement Emotions and Achievement Goals in Support of the Convergent, Divergent and Criterion Validity of the Spanish-Cognitive Test Anxiety Scale. International Journal of Educational Psychology, 6(1), 67-92. doi: 10.17583/ijep.2017.2268

To link this article: http://dx.doi.org/10.17583/ijep.2017.2268

\section{PLEASE SCROLL DOWN FOR ARTICLE}

The terms and conditions of use are related to the Open Journal System and to Creative Commons Attribution License (CC-BY). 


\section{Achievement Emotions and Achievement Goals in Support of the Convergent, Divergent and Criterion Validity of the Spanish-Cognitive Test Anxiety Scale}

Javier Sánchez Rojas

National University of Cordoba
Luis Alberto Furlan

National University of Cordoba

\section{Abstract}

Based on the control-value theory of achievement emotions and theory of achievement goals, this research provides evidence of convergent, divergent, and criterion validity of the Spanish Cognitive Test Anxiety Scale (S-CTAS). A sample of Argentinean undergraduates responded to several scales administered at three points. At time 1 and 3, the sample responded to scales designed to assess their adoption of mastery and performance goals. At time 2, they responded to the SCTAS and items assessing their anxiety and shame in class, and their enjoyment, hopelessness, shame, and anxiety experienced in exam. Results demonstrated the convergent and divergent validity of the S-CTAS through correlations with other class and test emotions scales measuring outcome and activity-emotions. Furthermore, the findings verified the criterion validity of the S-CTAS by estimating the predictive influence of achievement goals on cognitive test anxiety and other emotions, and in turn the effects of cognitive test anxiety and these emotions on achievement goals.

Keywords: cognitive test anxiety, achievement emotion, achievement goal, validity, scale

2017 Hipatia Press

ISSN: 2014-3591

DOI: $10.17583 /$ ijep.2017.2286

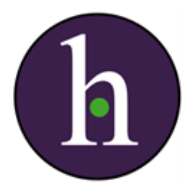




\section{Emociones de Logro y Metas en Apoyo de la Validez Convergente, Divergente y Criterio de la Versión en} Español de la Escala de Ansiedad Cognitiva frente a los Exámenes

Javier Sánchez Rojas

National University of Cordoba

Resumen

Basada en la teoría de control -valor de las emociones de logro y en la teoría de las metas de logro, esta investigación provee evidencias de validez convergente, divergente y de criterio para la Spanish Cognitive Test Anxiety Scale (S-CTAS). Una muestra de estudiantes argentino respondió diversas escalas administradas en tres momentos. En el momento 1 y 3 la muestra informó sobre sus metas de maestría o rendimiento. En el momento 2 respondieron la S-CTAS e informaron sobre su ansiedad y vergüenza en clase, y su disfrute, desesperanza, vergüenza y ansiedad experimentadas en exámenes. Los resultados demostraron la validez convergente y divergente de la S-CTAS mediante las correlaciones con otras escalas de emociones en clase y exámenes que miden emociones de resultados y de actividades. Adicionalmente, los resultados verifican la validez de criterio de la S-CTAS, mediante la estimación de la influencia predictiva de las metas de logro sobre la ansiedad cognitiva ante los exámenes y otras emociones, e inversamente, el efecto de la ansiedad cognitiva ante los exámenes y otras emociones sobre las metas de logro.

Palabras clave: ansiedad cognitiva ante los exámenes, emociones de logro, metas de logro, validez, escala

2017 Hipatia Press

ISSN: 2014-3591

DOI: $10.17583 /$ ijep.2017.2268

Hipatia Press

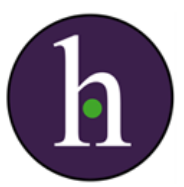


est anxiety is an emotional reaction experienced by people in evaluative settings that is accompanied by worries about the possibility of failure or poor performance and possible aversive consequences for self-esteem, social desirability and loss of an expected benefit (Gutiérrez Calvo \& Avero, 1995).

Researchers agree that the cognitive component of test anxiety, namely worry, is negatively related to academic achievement (Hembree, 1988; Zeidner, 2007). However, students with high test anxiety have a much broader spectrum of cognitive manifestations than merely worry. Cassady and Johnson (2002) advanced the construct of cognitive test anxiety to more accurately describe the cognitive manifestations of test anxiety. Cognitive test anxiety includes cognitions with the potential to interfere with optimal performance - such as the tendency to worry about poor performance, the experience of task irrelevant thoughts during the test and periods of study, comparisons with other peers during periods of test preparation or performance, and thoughts of escape that interfere with attention during the test taking. To assess this construct, researchers developed and validated the Cognitive Test Anxiety Scale (CTAS, Cassady \& Johnson, 2002).

The Spanish Cognitive Test Anxiety Scale (S-CTAS; Furlan, Casssady \& Pérez, 2009) is a Spanish adaptation of the Cognitive Test Anxiety Scale (Cassady \& Johnson, 2002). The S-CTAS estimates the cognitive manifestations of test anxiety in university students. Previous studies with the S-CTAS have provided evidence of construct validity based on explorations of the factor structure of the S-CTAS thorough exploratory and confirmatory factorial analyses, gender differences, and criterion validity through explorations of the measures ability to predict important outcomes including: (1) academic performance (Furlan et al, 2009), (2) attention selfregulation (Furlan, Kohan Cortada, Piemontesi \& Heredia, 2008), (3) dimensions of perfectionism and negative automatic thoughts (Moyano, 2010), (4) academic procrastination and mental symptoms (Furlan, Ferrero \& Gallart, 2014) and (5) behavioral manifestations of anxiety, such as avoidance or performance deficits during exams (Furlan, 2013). Additionally, normative values differentiated by gender for Argentine university students (Furlan, Pérez, Moyano \& Cassady, 2010) were estimated. The S-CTAS has also been successfully used in studies evaluating 
the effectiveness of psychoeducational interventions (Medrano \& Moretti, 2013). Nonetheless this proven evidence, additional studies demonstrating the validity of the instrument are required.

In this research, two studies designed to (a) provide evidence of convergent and divergent validity of the S-CTAS, and (b) verify criterion validity of the S-CTAS on a theoretical model that includes personal achievement goals and other achievement emotions are reported below.

\section{Convergent and Divergent Validity of the S-CTAS}

While theories and studies prevail which address single emotions (e.g., test anxiety; Zeidner, 2007), or single functions of emotions (e.g., their impact on cognitive processes; Ashby, Isen, \& Turken, 1999), more integrative approaches are largely lacking. The control-value theory of achievement emotions (Pekrun, 2006) offers an integrative framework for analyzing the antecedents and effects of emotions experienced in achievement and academic contexts.

In this theory, achievement emotions are defined as emotions tied directly to achievement activities (e.g., studying or test taking) or achievement outcomes (success and failure). Most emotions pertaining to attending class, studying, and writing tests and exams are seen as achievement emotions, since they relate to activities and outcomes that are typically judged according to competence-based standards of quality (Pekrun \& Perry, 2014). Two types of achievement emotions differing in object focus can thus be distinguished: activity emotions pertaining to ongoing achievement-related activities and outcome emotions pertaining to the outcomes of these activities (Pekrun, Goetz, Titz, \& Perry, 2002; Pekrun, Elliot, \& Maier, 2006, 2009). The latter include prospective, anticipatory emotions (e.g., hope for success, anxiety of failure), as well as retrospective emotions (e.g., pride or shame experienced after feedback of achievement). As with emotions more generally, achievement emotions can be conceptualized in trait or state-like ways. For example, habitual test anxiety as measured by traditional test anxiety scales is commonly regarded as a trait emotion, whereas anxiety experienced an hour before a specific exam would be viewed as a state emotion (Spielberger, Anton, \& Bedell, 1976). 
According to the S-CTAS, test anxiety is considered to be a specific situational trait that involves concern about potential negative outcomes that could occur before, during, and after an evaluative event. So studies of convergence and divergence should consider distinctions related to different aspects of emotion - such as trait (typically experienced by an individual), situational (attending class, studying, and writing tests and exams) and temporal specificity (prospective, retrospective). Further, according to the Pekrun's (2006) taxonomy of outcome emotions, the prospective and retrospective, positive and negative (valence) emotions can be distinguished. The prospective emotions include hope (positive), anxiety and hopelessness (negative), whereas the retrospective emotions contain shame (negative), pride and relief (positive).

In order to provide evidence of convergent validity, scores of the SCTAS and scales measuring test-anxiety and other prospective (hopelessness) and retrospective (shame) outcome-emotions aroused by test situations should be correlated. Additional evidence could be achieved by correlating the S-CTAS with scales that assess negative outcome emotions in other relevant academic situations as attending classes (anxiety, shame). Because the situations differ, the size of the relationship between emotions experienced in class and S-CTAS should be lower than the relationship between emotions experience during a testing event and S-CTAS. On the other hand, divergent evidence could be obtained by exploring the relationship between scores on the S-CTAS and activity-related emotions experienced during test taking - such as enjoyment. In this case, due the object and valence change, the size of the relationship between testenjoyment and S-CTAS should be even smaller and negative.

\section{Criterion Validity of the S-CTAS: Achievement Goals, Anxiety and other Achievement Emotions}

The interplay between achievement goals and emotions has been acknowledged since the inception of achievement goal theory (Dweck \& Leggett, 1988) and current research on achievement emotions has integrated conceptualizations of achievement goal theory. The model proposed by Pekrun and his colleagues (Elliot \& Pekrun, 2007; Pekrun et al., 2006, 2009) 


\section{Sánchez-Rosas \& Furlan-S-Cognitive Test Anxiety Scale}

extends Pekrun's (2006, Pekrun \& Perry, 2014) control-value theory of emotions by articulating how achievement goals and discrete achievement emotions are reciprocally related (see Linnenbrink \& Pintrich, 2002 for the asymmetrical bidirectional model). Specifically, achievement goals facilitate different types of appraisals related to desired and undesired results, and these appraisals contribute to the arousal of different types of emotions (e.g., anxiety, shame, hopelessness, enjoyment). In turn, it is postulated that these same emotions would have retroactive effects on personal achievement goals (Pekrun, 2006) by focusing attention on goals congruent with emotional arousal. However, this hypothesis has not been tested yet been empirically tested (Linnenbrink-Garcia \& Barger, 2014).

Before turning to our proposed model relating achievement goals and emotions in order to test the criterion validity of the S-CTAS, it is important to note that some empirical investigations have examined the relation between goals and affect (see Huang, 2011; Linnenbrink-Garcia \& Barger, 2014; Linnenbrink-Garcia \& Pintrich, 2002 for a more detailed review of the literature).

On one hand, mastery-based goals focus on the activity itself and the implications of ongoing experience with the activity for intrapersonal development. There is strong empirical support suggesting that masteryapproach goals relate positively to enjoyment (Daniels et al., 2008, 2009; King, McInerney, \& Watkins, 2012; Pekrun et al., 2006, 2009; SánchezRosas, 2015 a, b; Sánchez-Rosas \& Pérez, 2015; Sapio, 2010) and negatively to boredom (Daniels et al., 2008, 2009; King et al., 2012; Pekrun et al., 2006, 2009; Sánchez-Rosas, 2015 b). Several studies found a negative relation between mastery-approach and anxiety (Bandalos et al., 2003; Daniels et al., 2008, 2009; Shih, 2005, 2008). However, there were no significant relations in an equivalent number of studies (Bong, 2009; Linnenbrink, 2005; Pekrun et al., 2009; Putwain \& Symes, 2012; Sideridis, 2007). Somewhat surprisingly, there was a positive relationship between mastery-approach goals and anxiety in two studies (Gaudreau, 2012; Koul, Roy, Kaewkuekool, \& Ploisawashay, 2009).

Mastery-avoidance goals are presumed to focus on negative activity engagement. Thus Pekrun et al. $(2006,2009)$ posited that these goals would be a positive predictor of boredom and anger (Shih, 2008) and perhaps a 
negative predictor of enjoyment. However, mastery-avoidance goals were associated with several negative emotions, such as anxiety (Bong, 2009; Putwain \& Symes, 2012; Sideridis, 2008) and sadness (Sideridis, 2008). On the other hand, performance-based goals focus on normative outcomes in either prospective or retrospective ways.

Performance-approach goals are presumed to focus prospective attention on the possibility of attaining positive normative outcomes, and retrospective attention on the positive value of the normative outcome attained. These goals would be a positive predictor of prospective and retrospective emotions like hope and pride (King et al., 2012; Pekrun et al., 2009). Negative emotions, on the other hand, relate less consistently to performance-approach goals. Several studies have suggested that performance-approach goals are related to test anxiety (Bandalos et al., 2003; Bong, 2009; Daniels et al., 2008, 2009; Gaudreau, 2012; King et al., 2012; Koul et al., 2009; Linnenbrink, 2005; Sánchez-Rosas, 2015b). However, a small number found just the opposite (Duchesne \& Rattelle, 2010; Shih, 2005), and even more have found no relation at all (Pekrun et al., 2006, 2009; Putwain \& Symes, 2012; Shih, 2008; Sideridis, 2007). In addition, performance-approach goals relate positively to hopelessness and shame (King et al., 2012; Pekrun et al., 2006; Sánchez-Rosas, 2015a, b; Sánchez-Rosas \& Pérez, 2015).

Finally, performance-avoidance goals are presumed to focus prospective attention on the possibility of negative normative outcomes, and retrospective attention on the negative value of the normative outcome attained. Thus these goals are a positive predictor of anxiety (Bong, 2009; Duchesne \& Rattelle, 2010; Pekrun et al., 2006; 2009; Putwain \& Symes, 2012; Shih, 2008; Sideridis, 2007), hopelessness (Pekrun et al., 2006), and shame (Pekrun et al., 2009; Sánchez-Rosas, 2015a, b; Sánchez-Rosas \& Pérez, 2015).

Evidence of criterion validity for the S-CTAS could be achieved through a path analysis estimating the predictive influence of personal achievement goals (at Time 1) on the cognitive test anxiety and other emotions (hopelessness, shame, enjoyment) (at Time 2), and in turn the effects of cognitive test anxiety and these emotions on personal achievement goals (at Time 3). 
Next, two studies designed to (a) provide evidence of convergent and divergent validity of the S-CTAS, and (b) verify criterion validity of the SCTAS on a theoretical model that includes personal achievement goals and other achievement emotions are reported below.

\section{Method}

\section{Participants}

The sample was self-selected because the guest people decided whether or not to participate in the study (Sterba \& Foster, 2008). One hundred fifty two (91 \% female; $M=22.88$ years, $S D=6.05$ ) Argentinean undergraduates of Psychology, Languages, Social Sciences and Law (81\%), Chemistry, Economy, Math and Engineering (19\%) studying at the National University of Córdoba participated in the study. Distribution by gender represents the habitual distribution in the departments sampled.

\section{Measures}

Cognitive test anxiety. The Spanish cognitive test anxiety scale (SCTAS, Furlan, et al 2009) was applied to assess the level of cognitive test anxiety experienced during evaluative events. Responses to the S-CTAS ranged on a four-point Likert-type scale from 1 (not at all typical of me) to 4 (very typical of me). A sample item include: "Mind goes blank when pressured for answer on test".

Achievement goals (A-AGQ-R, Sánchez-Rosas, 2015a). The Argentinean Achievement Goal Questionnaire - Revised assesses the $2 \times 2$ achievement goal framework. Participants answered twelve items expressing the degree of agreement with each item on a scale of 1 (strongly disagree) to 5 (strongly agree). Here, dimensionality and internal consistency were tested and optimal results were obtained. At Time 1 and 3, subscales and internal consistencies were: mastery-approach (e.g., My aim is to completely master the material presented in this class, $\alpha=.67$ and .77), mastery-avoidance 
(e.g., My aim is to avoid learning less than I possibly could, $\alpha=.76$ and .74), performance-approach (e.g., My aim is to perform well relative to other students, $\alpha=.89$ and .95) and performance-avoidance (e.g., My aim is to avoid doing worse than other students, $\alpha=.88$ and .93). As masteryapproach and avoidance and performance-approach and avoidance were moderate to highly correlated, it was decided to create two new variables (i.e, mastery goals and performance goals) from the sum of both scales to create a more parsimonious measure of the constructs of interest.

Achievement emotions. This study employed six scales of Achievement Emotions Questionnaire-Argentine (AEQ-AR, Sánchez-Rosas, 2015b). For all the scales, one dimensionality and internal consistency were tested and acceptable results were obtained. Participants were asked to rate their emotional experiences of class anxiety (e.g., Thinking about class makes me feel uneasy, twelve items), class shame (e.g., When I say anything in class I feel like I am making a fool of myself, eleven items), test enjoyment (e.g., For me the test is a challenge that is enjoyable, ten items), test hopelessness (e.g., I feel so resigned about the exam that I can't start doing anything, twelve items), test shame (e.g., I am ashamed of my poor preparation, ten items), test anxiety (e.g., I get so nervous I can't wait for the exam to be over, twelve items) using five point Likert scale from 1 (never) to 5 (always).

The total scores of each scale were calculated by adding the values provided to each item and then divided by the number of items in the corresponding scale. In this way, the average values per variable were obtained, they go from 1 to 5 for all scales, in exception of cognitive test anxiety that adopts values from 1 to 4 .

Academic performance. The achievement motivation and emotion literatures have demonstrated the critical importance that performance attainment has in the interrelations between achievement goals and achievement emotion (Pekrun et al., 2009). In the present research, cumulative Grade Point Average was obtained which is considered an accurate measure of university student performance (Cassady, 2001). 


\section{Procedure}

Participants were contacted via e-mail and social networking sites, and all agreed to voluntarily complete the protocols administered through the online survey system LimeSurvey (Pérez, 2007). The protocols were administered at three points separated by two weeks during the first semester in an academic year. At Time 1, participants reported their cumulative Grade Point Average and completed the Argentinian Achievement Goals Questionnaire. At Time 2, participants responded to the Cognitive test anxiety scale and the class anxiety, class shame, test enjoyment, test hopelessness, test shame, test anxiety scales. At Time 3, participants were asked to complete the Argentinian Achievement Goals Questionnaire. Protocols were elaborated with consent added to the set of selected scales for this study. Participants provided informed consent prior to participation.

\section{Data Analysis}

A correlational-explicative, with repeated measures design was developed (Montero \& León, 2007). To provide evidence of convergent and divergent validity bivariate correlations were used.

In addition to bivariate correlation procedures, path analysis techniques were used to explore the relationship among the variables of interest. Path analysis is a statistical method used to evaluate the fit of causal models and to identify the direct and indirect contribution made by a set of independent variables to explain the variability of the dependent variables (Pérez, Medrano, \& Sánchez Rosas, 2014). A path analysis (maximum-likelihood estimation) was carried out in order to evaluate the reciprocal influences between achievement goals and test anxiety. Suggestions of Pérez et al. (2014) detailing how to appropriately interpret the fit indexes, direct, indirect effects, and significant path coefficients were followed. Model fit was assessed using the following indices ( $\mathrm{Hu} \&$ Bentler, 1995): chi-square degree of freedom ratio $(\chi 2 / \mathrm{df})$, comparative fit index (CFI), goodness fit 
index (GFI), incremental fit index (IFI), and root-mean square error of approximation (RMSEA). The following criteria were used to evaluate the adequacy of model fit: $\chi 2 / \mathrm{df} \leq 2.0$ (Hair, Anderson, Tatham, \& Black, 1995), $\mathrm{CFI} \geq .90, \mathrm{GFI} \geq .90, \mathrm{IFI} \geq .90$, and RMSEA $\leq .08$ (Browne \& Cudeck, 1993).

The IBM SPSS Amos 19 (Arbuckle, 2010) program was used to conduct the statistical analysis according to proposed objectives.

\section{Results}

Prior to the central analysis, an initial exploration of all items was conducted to evaluate missing values, univariate and multivariate atypical cases, and normal univariate distributions. Any missing values were found. Then, univariate and multivariate atypical cases were determined by calculating the standard $\mathrm{z}$ score for each variable (z scores $>3.29$ were considered atypical) and the Mahalanobis distance measure (considering $\mathrm{p}<.001$ an atypical case). Any cases identified using these methods were discarded. Across variables, the values for asymmetry and kurtosis were between -2 and +2 , which are considered acceptable in order to prove normal univariate distribution (George \& Mallery, 2010). Finally, the items were averaged within each scale to create indices of all variables.

\section{Convergent and divergent validity of the S-CTAS}

Table 1 shows the means, standard deviations and correlations between the variables evaluated in this study. 
78 Sánchez-Rosas \& Furlan-S-Cognitive Test Anxiety Scale

Table 1.

Descriptive statistics and bivariate correlations

\begin{tabular}{|c|c|c|c|c|c|c|c|c|c|c|c|c|}
\hline & 1 & 2 & 3 & 4 & 5 & 6 & 7 & 8 & 9 & 10 & 11 & 12 \\
\hline 1. cta & .91 & & & & & & & & & & & \\
\hline 2. $\operatorname{tax}$ & $.74^{* *}$ & .92 & & & & & & & & & & \\
\hline 3. cax & $.54^{* *}$ & $.52^{* *}$ & .89 & & & & & & & & & \\
\hline 4. thl & $.73^{* *}$ & $.68^{* *}$ & $.45^{* *}$ & .95 & & & & & & & & \\
\hline 5. tsh & $.75^{* *}$ & $.69^{* *}$ & $.63^{* *}$ & $.74^{* *}$ & .93 & & & & & & & \\
\hline 6. $\operatorname{csh}$ & $.45^{* *}$ & $.50^{* *}$ & $.65^{* *}$ & $.42^{* *}$ & $.63^{* *}$ & .90 & & & & & & \\
\hline 7. tjo & $.31^{* *}$ & $.32^{* *}$ & -.06 & $.38^{* *}$ & $.22^{* *}$ & $-.15^{*}$ & .87 & & & & & \\
\hline 8. mal & $.10^{*}$ & .08 & -.09 & -.10 & .01 & -.07 & $.27^{* *}$ & .70 & & & & \\
\hline 9. pe1 & $.16^{*}$ & $.17^{*}$ & $.22^{* *}$ & .07 & $.24^{* *}$ & $.20^{*}$ & .11 & $.37^{* *}$ & .93 & & & \\
\hline 10. $\mathrm{ma} 3$ & $.19^{*}$ & $.26^{* *}$ & .05 & .05 & .11 & .05 & $.23^{* *}$ & $.63^{* *}$ & $.28^{* *}$ & .74 & & \\
\hline 11. pe3 & $.25^{* *}$ & $.26^{* *}$ & $.24^{* *}$ & .10 & $.31^{* *}$ & $.22^{* *}$ & .13 & $.35^{* *}$ & $.87^{* *}$ & $.36^{* *}$ & .96 & \\
\hline 12. gра & $\begin{array}{l}- \\
.37^{* *}\end{array}$ & $.22^{* *}$ & $.25^{* *}$ & $-37^{* *}$ & $-34^{* *}$ & $-.18^{*}$ & .02 & -.01 & $-.19^{*}$ & -.10 & -.13 & - \\
\hline M & 1.99 & 2.94 & 1.89 & 1.90 & 2.03 & 2.32 & 2.56 & 3.94 & 2.47 & 3.91 & 2.22 & 6.22 \\
\hline SD & 0.56 & 0.86 & 0.65 & 0.79 & 0.83 & 0.80 & 0.73 & 0.69 & 1.07 & 0.68 & 1.07 & 1.39 \\
\hline
\end{tabular}

Note. cta $=$ cognitive test anxiety, $\operatorname{tax}=$ test anxiety, thl $=$ test hopelessness, tsh $=$ test shame, cax = class anxiety, $\mathrm{csh}=$ class shame, tjo = test enjoyment. $\mathrm{M}=$ mean, $\mathrm{SD}=$ standard deviation. ${ }^{*} \mathrm{p}<.05,{ }^{* *} \mathrm{p}<.01$. Cronbach's alphas are on the diagonal.

\section{Criterion Validity of the S-CTAS: Achievement Goals, Cognitive Test Anxiety and Achievement Emotions}

A theoretical model (see Figure 1) in which achievement goals predict test emotions and, in turn, these predict achievement goals was specified as 
follows: (a) academic performance is a negative predictor of performance goals, hopelessness, shame, and cognitive test anxiety, (b) mastery goalsTime 1 positively predict mastery goals-Time 3 and enjoyment and this, in turn, predicts mastery goals-Time 3 , (c) performance goals-Time 1 positively predict performance goals-Time 3 and hopelessness, shame, and cognitive test anxiety and that these emotions, in turn, influence performance goals-Time 3, (d) given the larger number of studies that found relations between mastery goals and cognitive test anxiety, a plausible relation was supposed where mastery goals-Time 1 would predict cognitive test anxiety which, in turn, would predict mastery goals-Time 3.

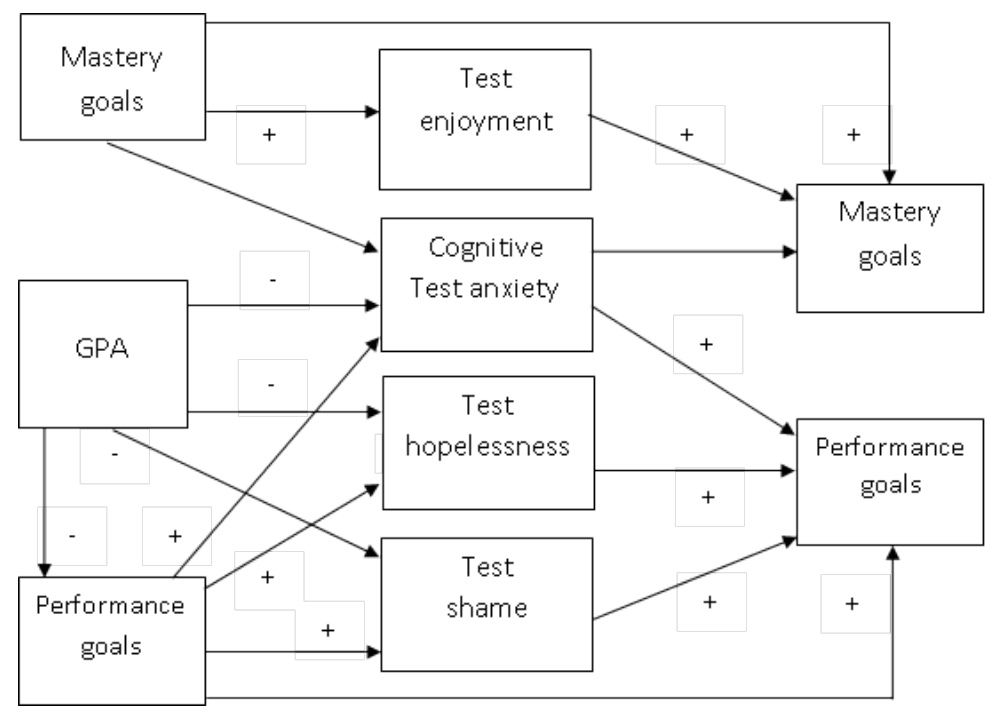

Time 1

Time 2

Time 3

Figure 1. Hypothesized model depicting the relationships between achievement goals and emotions. 
The fit indexes suggested the proposed model provide adequate fit to the observed data $\left(\chi^{2} / d f=1.29\right.$, IFI $=.99$, GFI $=.97$, CFI $=.99$, RMSEA $=$ .044 ), and thus the feasibility of a model relating achievement goals and emotions is evidenced. Figure 2 shows the standardized solution, including proportion of explained variance for each variable. Non-significant paths from performance goals to cognitive test anxiety and test hopelessness have been suppressed in order to simplify the presentation.

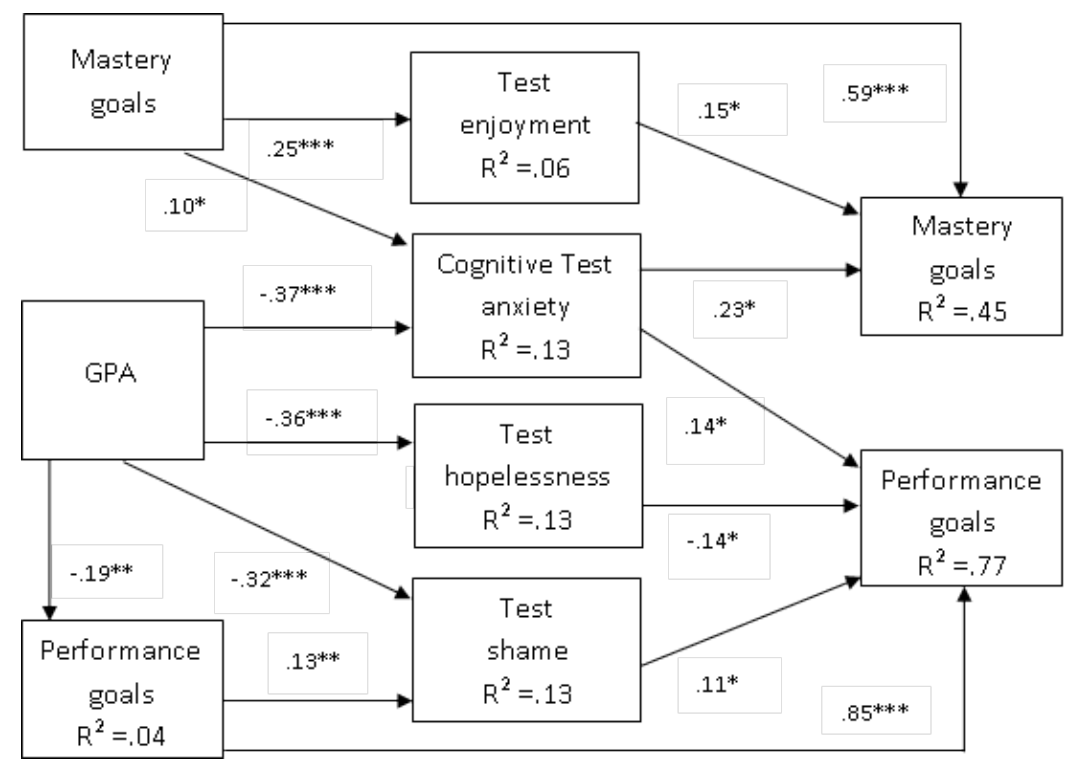

$\begin{array}{lll}\text { Time } 1 & \text { Time } 2 & \text { Time } 3\end{array}$

Figure 2. Standardized model for achievement goals and emotions.

\section{Discussion}

Adapting an instrument of psychological measurement supposes a process that involves multiple empirical studies oriented to gather reliability and 
validity evidences. In successive investigation such evidence was obtained through analytical approaches of increasing complexity that demonstrate the psychometric properties of the S-CTAS. Moreover, the S-CTAS was implemented in studies that included relationships with constructs derived from different theories which supported the development of the measure (Furlan, 2013; Furlan et al, 2008, 2009, 2010, 2014; Medrano \& Moretti, 2013; Moyano, 2010).

Here, the reported results provide some additional evidence of the convergent and divergent validity of the S-CTAS through examinations of the relationship between cognitive test anxiety and other class and test emotions scales. Furthermore, the findings verify the criterion validity of the S-CTAS on a theoretical model that included personal achievement goals and other achievement emotions such as test-related enjoyment, shame, and hopelessness (Pekrun, Goetz, Perry, Kramer, \& Hochstadt, 2004).

\section{Convergent and divergent validity of the S-CTAS}

Theoretically, tests and exams can be expected to trigger a wide variety of human emotions. Exam results are decisive for educational and occupational careers today, implying that high subjective values are attached to success and failure on exams. Since emotions are caused by events and objects bearing high positive or negative values, exams can be expected to trigger intense emotions. Exams are events which can be anticipated and recalled, implying that they can induce both prospective and retrospective emotions (Pekrun et al., 2004). According to this, we tested the convergent and divergent relations between anxiety and shame, hopelessness, and enjoyment, in test or class situations.

Correlations between measures of cognitive test anxiety (S-CTAS) and those made by another scale that assesses one-dimensional manifestation of test anxiety are very high, which provides evidence of the convergent validity of the S-CTAS. Also, scores of other scales evaluating negative emotions aroused by negative outcomes in testing situations, such as hopelessness and shame, showed similar correlations in magnitude and direction with the S-CTAS. Moreover, these magnitudes are similar to those observed by Pekrun et al. (2004, 2011). In doing so, it confirms the Pekrun's 


\section{Sánchez-Rosas \& Furlan-S-Cognitive Test Anxiety Scale}

(2006) taxonomy that states that emotions can be organized according to their object, valence and situational and temporal specificity. As measured in this research, anxiety, hopelessness and shame are negative-outcome emotions experienced in exams. Whereas anxiety and hopelessness are prospective emotions with uncertainty expectancies about failure and certainty of failure, shame differs in that is a retrospective emotion involving retrospective appraisals of poor performance during and after the exam. The similar correlations in magnitude may imply that, independent of the temporal specificity, all the negative emotions experienced in test and aroused by negative outcomes co-exist with the similar frequency, as Pekrun et al. (2004) informed. In other hand, test-related anxiety, hopelessness, and shame also share many elements (e.g., failure-related worry cognitions, Pekrun et al., 2004).

Two other correlations of S-CTAS scores with those obtained by measuring anxiety and shame in class were obtained. These correlations are lower than the above because the specific situation that arouses emotion is changed. It is known that class attendance involves less pressure for achievement and more autonomy than writing an exam (Pekrun, 2007). This would explain these differential correlations respect to test situations. Nonetheless, the relationship with anxiety in class is greater than with the shame in class, which is consistent since a different emotion it is estimated.

Finally, the correlation with the CTAS obtained by measuring test enjoyment was weak and negative, and this magnitude is fairly close to those informed by Pekrun et al. (2004, 2011). As mentioned above, enjoyment is an activity-related emotion experienced during the test taking involving enjoyment of the challenge implied by an exam. As the object and valence change, the negative and low relationship between test enjoyment and test anxiety is clear evidence of divergent validity.

\section{Criterion Validity of the S-CTAS: Achievement Goals, Cognitive Test Anxiety and Achievement Emotions}

As seen in Figure 1, criterion validity was evidenced by the theoretical model in which achievement goals (and academic performance) (Time 1) predicted test emotions (Time 2) and, in turn, these predict achievement 
goals (Time 3). Although the contribution to the variability of emotions is low, the goal variability explained by the antecedents (goals and emotions) is moderate to high. In consequence, relevant variables were included for the explanation of the achievement goals. Also, these results reveal the contribution of the measurements made by cognitive test anxiety to explain achievement goals. Specifically, cognitive test anxiety positively predicted performance goals and mastery goals, although the magnitude of the effect is low. Furthermore, both the mastery goals and the performance goals at the Time 1 were associated with the mastery goals and performance goals at the Time 3, demonstrating the stability of the goals (Zusho, Karabenick, Bonney, \& Sims, 2007). The short temporal distance between Time 1 and Time 3 (four weeks) would, mainly, determining the observed stability.

Like many other researches (Church, Elliot, \& Gable, 2001; Elliot \& McGregor, 2001; Finney, Pieper, \& Barron, 2004; Pekrun et al., 2002, 2004, 2009; Vansteenkiste et al., 2004; Wolters, 2004; Zeidner, 2007), a negative relation was attested from academic performance to performance goals, hopelessness, shame, and anxiety. Then, the lower academic achievement oriented students towards adopting performance goals. Moreover, the lower attainment would have facilitated appraisals related to undesired results, and these appraisals would have contributed to the arousal of negative outcome related emotions like hopelessness, shame, and anxiety.

While much research inquired the influence of achievement goals on achievement emotions, it is generally assumed, although not studied, that achievement goals influence achievement emotions which in turn influence achievement goals (Pekrun, 2006). This relation would complete the dynamic cycle of reciprocal influence between achievement goals and achievement emotions. As hypothesized, mastery goals predicted enjoyment and this, in turn, predicted mastery goals. This is because mastery goals focus on the process of the achievement activity in itself and enjoyment is experienced while performing a task. So, mastery goals lead to students seek mastering the task, and this would lead them to enjoy the class and be excited about learning (Pekrun et al., 2006, 2009). Then, the enjoyment is characterized by attributing the success to mastering the task itself, and this perceived control allows the student to seek mastering the task. 


\section{Sánchez-Rosas \& Furlan-S-Cognitive Test Anxiety Scale}

As it was expected, performance goals positively explained shame and this, in turn, positively predicted performance goals. Performance goals involve concerns by the normative results and these concerns have demonstrated be responsible of the negative appraisals of control that arouse shame (Pekrun et al., 2006, 2009; Sánchez- Rosas, 2015a; Sánchez-Rosas \& Pérez, 2015), since shame involves worries about exposing students' incompetence in comparison the others. Once activated shame, it is more likely that students adopt goals focused in the normative performance.

On the other hand, performance goals at Time 1 did not predict anxiety and hopelessness. However, according to our hypothesis and other studies, anxiety (Bandalos et al., 2003; Bong, 2009; Daniels et al., 2008, 2009; Duchesne \& Rattelle, 2010; Gaudreau, 2012; King et al., 2012; Koul et al., 2009; Linnenbrink, 2005; Pekrun et al., 2006, 2009; Putwain \& Symes, 2012; Shih, 2005, 2008; Sideridis, 2007) positively predicted performance goals at the Time 3, evidencing criterion validity for the S-CTAS. Surprisingly, and contrary to the expectations (King et al., 2012; Pekrun et al., 2006), hopelessness becomes a negative predictor of performance goals. When students have doubts as to their ability to control their test performance, and if success is perceived as not being attainable and failure to be certain, they are more likely to experience negative emotions such as anxiety or hopelessness (Pekrun, 2006). On one hand, this lack of controllability regarding future outcomes (uncertainty) could lead to the adoption of outcome-related goals, maybe in the hope of controlling the subsequent attainment. But, on the other hand, the certainty concerning future failure that is inherent to hopelessness could decrease the performance goals because nothing could be done to control the performance.

Similar to other studies (Bong, 2009; Gaudreau, 2012; Koul et al., 2009; Putwain \& Symes, 2012; Sideridis, 2008), mastery goals at the Time 1 positively predicted cognitive test anxiety and this, in turn, positively predicted mastery goals at the Time 3 . It is important to note, however, that negative achievement emotions are not always detrimental (i.e., they do not always produce negative effects; Pekrun, 2006). On one hand, as in this case, the motivation (mastery goals at the Time 1) may determine an emotional response mobilizing the resources needed to achieve mastery. On the other hand, the negative activating emotion, such as the test anxiety, could actually 
increase one's motivation (mastery goals at the Time 3) to study and prepare for the test (Artino \& Jones, 2012). In this case, a negative activating emotion has effectively facilitated mastery goals, which could have a positive overall effect on future learning and performance (Pekrun, 2006) These results demonstrate that the association between anxiety-mastery goals and hopelessness-performance goals can be quite complex, resulting from dynamic, reciprocal interactions between affect, cognition, and behavior (Linnenbrink \& Pintrich, 2004).

In sum, the scope of the reported studies are important, while increasing the available evidence of validity for the Spanish cognitive test anxiety scale (Furlan, 2013; Furlan et al, 2008, 2009, 2010, 2014; Medrano \& Moretti, 2013; Moyano, 2010). which demonstrates the usefulness of the instrument for research.

Although the reported results have the potential to increase our understanding of the topics under investigation, they should be considered with caution. While the evidence provided is theoretically and empirically strong, the observed criterion validity evidence has some limitations.

In analyzing the criterion validity, the model did not discriminate between the approach and avoidance dimensions of the achievement goals (Elliot \& Murayama, 2008). Consequently, the positive and negative features of both dimensions could not be distinguished. However, not being a purely theoretical investigation, it was considered sufficient and more parsimonious to analyze a smaller number of variables to provide criterion validity. This decision was based on moderate and high relationship of different achievement goals. Added to this, a model of partial mediation was not assessed, but simultaneously the intervening effects, the variance explained and the model fit, were assessed. It may be interesting to test the direct influence of achievement goals at Time 1 on achievement goals at Time 3 separate from the mediating variables tested here to see how much of a change is influenced by those variables.

Also, gender differences are an important aspect not addressed in this research. Sánchez-Rosas (2013) found unfavorable differences for women in achievement-related anxiety, shame, and hopelessness. Consequently, for a more rigorous analysis of the scale should be considered gender differences. The sample had a strong presence of women and psychology and social 
sciences students. Both factors could introduce bias into the examination and should be controlled for in future investigations. Future research should ensure the minimum sample sizes and multi-group analyses should also be conducted to establish that the scales demonstrate the same or different results.

\section{References}

Arbuckle, J. L. (2010). IBM SPSS Amos 19 User's Guide. Chicago, IL: IBM. Artino Jr., A. R., \& Jones II, K. D. (2012). Exploring the complex relations between achievement emotions and self-regulated learning behaviors in online learning. Emotions in Online Learning Environments, 15(3), 170-175. doi:10.1016/j.iheduc.2012.01.006

Ashby, F. G., Isen, A. M., \& Turken, A. U. (1999). A neuropsychological theory of positive affect and its influence on cognition. Psychological Review, 106, 529-550.

Bandalos, D. L., Finney, S. J., \& Geske, J. A. (2003). A model of statistics performance based on achievement goal theory. Journal of Educational Psychology, 95(3), 604-616. doi:10.1037/00220663.95.3.604

Bong, M. (2009). Age-related differences in achievement goal differentiation. Journal of Educational Psychology, 101(4), 879-896. doi:10.1037/a0015945.879

Browne, M. W., \& Cudeck, R. (1993). Alternative ways of assessing model fit. In: K. A. Bollen \& J. S. Long (Eds.), Testing structural equation models (pp. 136-162). Beverly Hills, CA: Sage.

Cassady, J. C. (2001). Self-Reported GPA and SAT: A Methodological Note. Practical Assessment, Research, and Evaluation, 7(12).

Available online: http://pareonline.net/getvn.asp?v=7\&n=12

Cassady, J. C., \& Johnson, R. E. (2002). Cognitive test anxiety, procrastination, and academic performance. Contemporary Educational Psychology, 27, 270-295.

Church, M. A., Elliot, A. J., \& Gable, S. L. (2001). Perceptions of classroom environment, achievement goals, and achievement outcomes. Journal of Educational Psychology, 93, 43-54.

Daniels, L. M., Haynes, T. L., Stupnisky, R. H., Perry, R. P., Newall, N. E., \& Pekrun, R. (2008). Individual differences in achievement goals: A 
longitudinal study of cognitive, emotional, and achievement outcomes. Contemporary Educational Psychology, 33(4), 584-608. doi:10.1016/j.cedpsych.2007.08.002

Daniels, L. M., Stupnisky, R. H., Pekrun, R., Haynes, T. L., Perry, R. P., \& Newall, N. E. (2009). A longitudinal analysis of achievement goals: From affective antecedents to emotional effects and achievement outcomes. Journal of Educational Psychology, 101(4), 948-963.

Duchesne, S., \& Ratelle, C. F. (2010). Parental behaviors and adolescents' achievement goals at the beginning of middle school: Emotional problems as potential mediators. Journal of Educational Psychology, 102, 497-507. doi:10.1037/a0019320

Dweck, C., \& Leggett, E. (1988). A social-cognitive approach to motivation and personality. Psychological Review, 95, 256-273.

Elliot, A. J., \& McGregor, H. A. (2001). A 2 x 2 achievement goal framework. Journal of Personality and Social Psychology, 80, 501519.

Elliot, A. J., \& Murayama, K. (2008). On the measurement of achievement goals: Critique, illustration, and application. Journal of Educational Psychology, 100, 613-628. doi:10.1037/0022-0663.100.3.613

Elliot, A. J., \& Pekrun, R. (2007). Emotion in the hierarchical model of approach-avoidance achievement motivation. In P. A. Schutz \& R. Pekrun (Eds.), Emotion in education (pp. 53-69). San Diego: Elsevier Inc. doi:10.1037/a0019320

Finney, S. J., Pieper, S. L., \& Barron, K. E. (2004). Examining the psychometric properties of the Achievement Goals Questionnaire in a general academic context. Educational and Psychological Measurement, 64, 365-382. doi:10.1177/0013164403258465

Furlan, L. (2013). Construcción de una escala conductual de ansiedad frente a los exámenes. Psiencia. Revista Latinoamericana de Ciencia Psicológica, 5(2), 81-89. doi:10.5872/psiencia/5.2.24

Furlan, L.; Cassady, J.C. \& Pérez, E. (2009). Adapting the Cognitive Test Anxiety Scale for use with Argentinean University Students. International Journal of Testing, 9(1), 3-19. doi:10.1080/15305050902733448 
Furlan, L.; Kohan Cortada, A.; Piemontesi, S. \& Heredia, D. (2008). Autorregulación de la Atención, Afrontamiento y Ansiedad ante los Exámenes en estudiantes universitarios. XV Jornadas de Investigación y IV Encuentro de Investigadores en Psicología del Mercosur. Facultad de Psicología, Universidad de Buenos Aires, (pp. 246-247).

Furlan, L.; Pérez, E.; Moyano, M. \& Cassady, J.C. (2010). Propiedades psicométricas y estandarización de la Escala de Ansiedad Cognitiva frente a los Exámenes a la población universitaria argentina. Evaluar, 10, 22-31.

Furlan, L.; Ferrero, M.J. \& Gallart, G. (2014). Ansiedad frente a los exámenes, procrastinación y síntomas mentales en estudiantes de la Universidad Nacional de Córdoba. Revista Argentina de Ciencias del Comportamiento, 6(3), 31-39.

Gaudreau, P. (2012). Goal self-concordance moderates the relationship between achievement goals and indicators of academic adjustment. Learning and Individual Differences, 22(6), 827-832. doi:10.1016/j.lindif.2012.06.006

George, D., \& Mallery, M. (2010). SPSS for Windows Step by Step: A Simple Guide and Reference, 17.0 update (10a ed.). Boston: Pearson. Gutiérrez Calvo, M., \& Avero, P. (1995). Ansiedad, estrategias auxiliares y comprensión lectora: déficit de procesamiento vs falta de confianza. Psicothema, 7(3), 569-578.

Hair, J. F. J., Anderson, R. E., Tatham, R. L., \& Black, W. C. (1995). Multivariate data analysis (4th ed.). Saddle River, NJ: Prentice Hall.

Hembree, H. (1988). Correlates, causes, effects and treatment of test anxiety. Review of educational research, 58, 47-77.

Hu, L. T., \& Bentler, P. M. (1995). Evaluating model fit. In R. Hoyle (Ed.), Structural equation modeling: Concepts, issues, and applications (pp. 76-99). Thousand Oaks, CA: Sage.

Huang, C. (2011). Achievement Goals and Achievement Emotions: A Metaanalysis. Educational Psychology Review, 23(3), 359-388. doi:10.1007/s10648-011-9155-x

King, R. B., McInerney, D. M., \& Watkins, D. A. (2012). How you think about your intelligence determines how you feel in school: The role of 
theories of intelligence on academic emotions. Learning and Individual Differences, 22(6), 814-819. doi:10.1016/j.lindif.2012.04.005

Koul, R., Roy, L., Kaewkuekool, S., \& Ploisawaschai, S. (2009). Multiple goal orientations and foreign language anxiety. System, 37(4), 676688.

Linnenbrink, E. A. (2005). The dilemma of performance-approach goals:

The use of multiple goal contexts to promote students' motivation and learning. Journal of Educational Psychology, 97, 197-213. doi:10.1037/0022-0663.97.2.197

Linnenbrink, E. A., \& Barger, M. (2014). Achievement goals and emotions. In R. Pekrun \& L. Linnenbrink-Garcia (Eds.), Handbook of emotions in education (pp. 142-161). New York: Taylor \& Francis.

Linnenbrink, E. A., \& Pintrich, P. R. (2002). Achievement goal theory and affect: An asymmetrical bidirectional model. Educational Psychologist, 37, 69-78. doi:10.1207/S15326985EP3702_2 Linnenbrink, E. A., \& Pintrich, P. R. (2004). Role of affect in cognitive processing in academic contexts. In D. Y. Dai, \& R. J. Sternberg (Eds.), Motivation, emotion, and cognition: Integrative perspectives on intellectual functioning and development (pp. 57-87). Mahwah, NJ: Lawrence Erlbaum Associates.

Medrano, L. A. \& Moretti, L. (2013). Eficacia de un programa de entrenamiento para disminuir manifestaciones cognitivas de ansiedad ante los exámenes en ingresantes universitarios. Informes Psicológicos, 13(1), 41-51.

Montero, I., \& León O. G. (2007). A guide for naming research studies in psychology. International Journal of Clinical and Health Psychology, 7(3), 847-862.

Moyano, M. (2010). Ansiedad ante los Exámenes, Pensamientos Automáticos Negativos y Perfeccionismo en Estudiantes de la UNC. Tesina de Licenciatura. Inédita. Facultad de Psicología, Universidad Nacional de Córdoba, Argentina.

Pekrun, R. (2006). The control-value theory of achievement emotions: Assumptions, corollaries, and implications for educational research 
and practice. Educational Psychology Review, 18, 315-341. doi:10.1007/s10648-006-9029-9

Pekrun, R. (2007). Emotions in Students' Scholastic Development. In R. Perry \& J. Smart (Eds.), The Scholarship of Teaching and Learning in Higher Education: An Evidence-Based Perspective, 553-610. doi:10.1007/1-4020-5742-3_13

Pekrun, R., Elliot, A. J., \& Maier, M. A. (2006). Achievement goals and discrete achievement emotions: A theoretical model and prospective test. Journal of Educational Psychology, 98, 583-597.

Pekrun, R., Elliot, A. J., \& Maier, M. A. (2009). Achievement Goals and Achievement Emotions: Testing a Model of Their Joint Relations With Academic Performance. Journal of Educational Psychology, 101, 115-135. doi:10.1037/a0013383

Pekrun, R., Goetz, T., Frenzel, A., Barchfeld, P., \& Perry, P. (2011). Measuring emotions in students' learning and performance: The Achievement Emotions Questionnaire (AEQ). Contemporary Educational Psychology, 36, 36-48.

Pekrun, R., Goetz, T., Perry, R. P., Kramer, K., \& Hochstadt, M. (2004). Beyond test anxiety: Development and validation of the Test Emotions Questionnaire (TEQ). Anxiety, Stress and Coping, 17, 287316. doi:10.1080/10615800412331303847

Pekrun, R., Goetz, T., Titz, W., \& Perry, R. P. (2002). Academic emotions in students' self-regulated learning and achievement: A program of quantitative and qualitative research. Educational Psychologist, 37, 91-106. doi:10.1207/S15326985EP3702_4

Pekrun, R., \& Perry, R. P. (2014). Control-value theory of achievement emotions. In R. Pekrun \& L. Linnenbrink-Garcia (Eds.), Handbook of emotions in education (pp. 120-141). New York: Taylor \& Francis.

Pérez, C. J. M. (2007). Manual de Usuario de la plataforma de encuestas en línea: LimeSurvey. Versión 1.0, Licencia de Documentación Libre GNU.

Pérez, E., Medrano, L., \& Sánchez Rosas, J. (2014). Path Analysis: conceptos básicos y ejemplos de aplicación. Revista de la Asociación Argentina de Ciencias del Comportamiento, 5, 52-66. 
Putwain, D. W., \& Symes, W. (2012). Achievement goals as mediators of the relationship between competence beliefs and test anxiety. British Journal of Educational Psychology, 82(2), 207-224. doi:10.1111/j.2044-8279.2011.02021.x

Sánchez-Rosas, J. (2013). Búsqueda de Ayuda Académica, Autoeficacia Social Académica y Emociones de Logro en Clase en Estudiantes Universitarios. Revista Argentina de Ciencias del Comportamiento, 5, 35-41.

Sánchez-Rosas, J. (2015 a). Validation of the Achievement Goal

Questionnaire - Revised in Argentinean university students (A-AGQ-

R). International Journal of Psychological Research, 8(1), 10-23. doi:10.21500/20112084.641

Sánchez-Rosas, J. (2015 b). The Achievement Emotions QuestionnaireArgentine (AEQ-AR): internal and external validity, reliability, gender differences and norm-referenced interpretation of test scores. Evaluar, 15, 41-74.

Sánchez-Rosas, J. \& Pérez. E. (2015). Measuring threats, benefits, emotional costs and avoidance of academic help seeking in Argentinian university students. Pensamiento Psicológico, 13(2), 49-64. doi:10.11144/Javerianacali.PPSI13-2.mtbe

Sapio, M. (2010). Mastery goal orientation, hope, and effort among students with learning disabilities (unpublished doctoral dissertation). Fordham University, New York, NY.

Shih, S. (2005). Role of Achievement Goals in Children's Learning in Taiwan. The Journal of Educational Research, 98, 310-319. doi:10.3200/JOER.98.5.310-319

Shih, S. (2008). The Relation of Self-Determination and Achievement Goals to Taiwanese Eighth Graders' Behavioral and Emotional Engagement in Schoolwork. The Elementary School Journal, 108(4), 313-334. doi: $10.1086 / 528974$

Sideridis, G. D. (2007). Why Are Students With LD Depressed? A Goal Orientation Model of Depression Vulnerability. Journal of Learning Disabilities, 40(6), 526-539. doi:10.1177/00222194070400060401 
Sideridis, G. D. (2008), The regulation of affect, anxiety, and stressful arousal from adopting mastery-avoidance goal orientations. Stress and Health, 24, 55-69. doi:10.1002/smi.1160

Sterba, S. K., \& Foster, E. M. (2008). Self-selected sample. In P. J. Lavrakas (Ed.), Encyclopedia of Survey Research Methods (pp. 806-808).

Thousand Oaks, California: SAGE Publications. doi:10.4135/9781412963947.n525

Spielberger C.D., Anton, W.D., \& Bedell, J. (1976). The nature and treatment of test anxiety. In M. Zuckerman \& C.D. Spielberger (Eds.), Emotions and anxiety: New concepts, methods, and applications (pp.317-345). New York: Erlbaum/Wiley.

Vansteenkiste, M., Simons, J., Lens, W., Soenens, B., Matos, L., \& Lacante, M. (2004). Less is sometimes more: Goal content matters. Journal of Educational Psychology, 96, 755-764. doi:10.1037/00220663.96.4.755

Wolters, C. A. (2004). Advancing achievement goal theory: Using goal structures and goal orientations to predict students' motivation, cognition, and achievement. Journal of Educational Psychology, 96, 236-250. doi:10.1037/0022-0663.96.2.236

Zeidner, M. (2007). Test anxiety in educational contexts: Concepts, findings, and future directions. In P. A. Schutz \& R. Pekrun (Eds.), Emotion in education (pp. 165-184). San Diego, CA: Academic Press.

Zusho, A., Karabenick, S. A., Bonney, C. R, \& Sims, B, C. (2007).

Contextual determinants of motivation and help seeking in the college classroom. In R. Perry \& J. Smart (eds.), The Scholarship of Teaching and Learning in Higher Education: An Evidence-Based Perspective. London: Springer.

Javier Sánchez Rosas is Researcher in the Psychological and Educational Assessment Laboratory. National University of Cordoba Luis Alberto Furlan is Researcher in the Psychological and Educationa Assessment Laboratory. National University of Cordoba

Contact Address: Laboratorio de Evaluación Psicologica y Educativa. Enfermera Gordillo s/n Facultad de Psicología. Ciudad Universitaria. Córdoba 5000. Argentina 
Instructions for authors, subscriptions and further details:

http://ijep.hipatiapress.com

\section{Rethinking Education through Critical Psychology Cooperative Schools, Social Justice and Voice}

Nagore Navarrete Herrero ${ }^{1}$

1) University of Barcelona, Spain

Date of publication: February $24^{\text {th }}, 2017$

Edition period: February 2017 - June 2017

To cite this review: Navarrete Herrero, N. (2017). [Review of the book Rethinking Education through Critical Psychology Cooperative Schools, Social Justice and Voice by Davidge, G.] International Journal of Educational Psychology, 6(1), 93-95. doi: 10.17583/ijep.2017.2550

To link this review: http://dx.doi.org/10.17583/ijep.2017.2550

\section{PLEASE SCROLL DOWN FOR ARTICLE}

The terms and conditions of use are related to the Open Journal System and to Creative Commons Attribution License (CC-BY). 
IJEP - International Journal of Educational Psychology, Vol. 6 No. 1 February 2017 pp. 93-95

\section{Review}

Davidge, G. (2017). Rethinking Education through Critical Psychology Cooperative Schools, Social Justice and Voice. London: Routledge.

In this innovative book, Rethinking Education Through Critical Psychology, Gail Davidge makes a critical ethnographic analysis about the "co-operative" schools, which have been increasing from its birth in 2008 in England. Gail Davidge is a researcher who finished her $\mathrm{PhD}$ at the Education and Social Research Institute at Manchester Metropolitan University in the UK. With over ten years' experience, she mainly focuses her studies on a variety of Primary and Early Years educational settings.

Reforms in public education in England have allowed the appearance of this "co-operative" model of schooling as an alternative to the competitive educational model, which prevail in the present capitalist society. This flourishing system of education, through teaching values such as equality, honesty and solidarity, aims to achieve a more socially fair society.

Actually, there is a limited investigation about this recent nascent alternative model of public schooling. For this reason Gail Davidge, through eight chapters, gives to us a perspective about the unexplored relation between "co-operative" approaches to schooling and democratic subjectivity, attending to the "voice" of those involved in this school system. The result is achieved through a critical analysis of members' lived experiences, which have been different even opposing. Furthermore, she leads readers to reflect on how "co-operative" schools are established and developed to the aim of creates a dialogic debate space.

In order to contextualize the current socio-political situation of education and history of "co-operative" schools, the book begins by describing a theoretical framework which explores this complicated construction and its implications to social well-being and schooling. Is important to point out that to avoid revealing the identity of those participants who share their experiences and evading the identification of such "co-operative" schools, the author develops a fictionalized account derived from the real narratives, 
94 Navarrete - Rethinking Education through Critical Psychology Cooperative Schools, Social Justice and Voice [Book Review]

which took place mainly between September 2011 and July 2013. In addition, she exposes the ethical and methodological dilemmas, which appear as a consequence of analyse and represent people's lived experiences.

The importance of this text is founded in several issues. Firstly, by the representation of members' narratives, which far from reaching a common consensus about how are "co-operative" schools understood, what they do or how members live this alternative model, the author renders an approach of dissensus and opposite representations, which show the heterogeneity of numerous "voices" and different views of organize and live the "cooperative" education. Secondly, by the different proposals which are given to develop this model of schooling as a democratic and consolidated educational project, and finally, by the observed need of further critical investigation.

To elaborate the post-structural reading of "cooperative" schools, taking in account the deep difficulty of writing about personal experiences, the author relied on the limits of "voice" (Jackson \& Mazzei, 2009) and the failure of ethnography (Visweswaran, 1994).

The considerations presented in the book can be appealing for people involved in psychology, education, politics or social research, especially for students, researchers and practitioners who are interested in achieving a new egalitarian and socially fair model of education.

The book encourages people to carry out future investigations in order to create a dialogic space to discuss and lay the groundwork of "cooperative" schooling. Although it provides an insight about what it is for, and which benefits and losses could have this new way of report, more research is needed to support this form of education, which struggles for social justice and inclusion. 
IJEP - International Journal of Educational Psychology, 6(1) 95

\section{References}

Davidge, G. (2017). Rethinking Education through Critical Psychology Cooperative Schools, Social Justice and Voice. London: Routledge.

Jackson, A., \& Mazzei, L. (2009). Voice in qualitative inquiry: Challenging conventional, interpretive and critical conceptions in qualitative research. London: Routledge.

Visweswaran, K. (1994). Fictions Of Feminist Ethnography. Minneapolis: University of Minnesota Press.

Nagore Navarrete Herrero University of Barcelona nagore.navarrete.herrero@gmail.com 
Instructions for authors, subscriptions and further details:

http://ijep.hipatiapress.com

\section{List of Reviewers}

Date of publication: February $24^{\text {th }}, 2017$

Edition period: February 2017 - June 2017

To cite this article: IJEP Editors. (2017). List of Reviewers. International Journal of Educational Psychology, 6(1), 96. doi:10.17583/ijep.2017.2591

To link this article: http://dx.doi.org/10.17583/ijep.2017.2591

\section{PLEASE SCROLL DOWN FOR ARTICLE}

The terms and conditions of use are related to the Open Journal System and to Creative Commons Attribution License (CC-BY). 
IJEP - International Journal of Educational Psychology, Vol. 6 No. 1 February 2017 p. 96

\section{List of Reviewers}

We would like to thank all the scholars who served as reviewers for the International Journal of Educational Psychology over the year 2016. We deeply appreciate their contributions to the quality of this journal.

Rocío García-Carrión
Sandra Racionero-Plaza

Editors

Zainudin Abu Bakar

Anindito Aditomo

Antonio Aguilera

David Álvarez-García

Michelle Beth Bass

Christian Nathaniel Bwaya

Mihir Dash

Luana Ferreira

Daniel García-Pérez

Sandra Girbés

Walfredo González

Hernández

Ana Luisa López

Silvia Molina

Nagore Navarrete Herrero

Maria Padrós Cuixart
Cristina Pulido

Henar Rodriguez

Heidi Sairanen

Sopheak Song

Sanja Tataloviä Vorkapiä

Itxaso Tellado

Mireia Tintore

Leire Ugalde

Beatriz Valverde

Lourdes Villardón

Lan Yang 